\title{
A systematic review and meta-analysis of dietary fat effects on reproductive performance of sows and growth performance of piglets
}

\author{
Lixue Wang ${ }^{1}$, Shuai Zhang ${ }^{1}$, Lee J. Johnston ${ }^{2}$, Crystal L. Levesque ${ }^{3}$, Jingdong Yin ${ }^{1}$ and Bing Dong ${ }^{1 *}$ (D)
}

\begin{abstract}
Effects of added fat in sow diets on the sows' reproductive performance and offspring growth performance are influenced by multiple factors such as genetics, nutrition, parity, ambient temperatures, and farm management. Individual studies cannot cover all these factors. With the view to address this challenge, we searched all studies that were published from 1986 to 2020, and performed a systematic review and meta-analysis on the fat effect. In total, 19 papers were collected and analyzed. Fat supplementation in sow diets during late gestation and lactation decreased average daily feed intake $(\mathrm{ADFI}, P<0.05)$ and tended to increase average daily energy intake (ADEl, $P=$ 0.11). It had no impact on litter weights at birth $(P=0.40)$ or weaning $(P=0.46)$. It increased total numbers of piglets at birth $(P=0.07)$, but had no effect on liveborn per litter $(P=0.90)$ or survival rate $(P=0.48)$ of piglets to weaning. Fat supplementation had no significant effect on sow body weight loss $(P=0.67)$ or backfat thickness changes $(P=0.66)$, but sows fed diets with added fat had increased milk fat concentration $(P=0.03)$ and shorter wean to estrus intervals $(W E I, P=0.01)$. In specific circumstances, fat supplementation tended to improve growth performance of piglets with low litter weights at birth $(P=0.14)$, or when the sows lost large amounts of body weight during lactation $(P=0.11)$. The level of supplemented fat was $10 \%$ and higher would decrease liveborn per litter at neutral temperature $(P=0.10)$. The meta-analysis revealed that fat supplementation to sows diet during late gestation and lactation can be beneficial for sow reproductive performance and litter growth performance.
\end{abstract}

Keywords: Diets, Fat, Growth performance, Piglets, Reproductive performance, Sows

\section{Introduction}

Genetic selection and improvements in health, management and nutrition have led to dramatic increases in sow productivity $[1,2]$. With improved productivity, sows often mobilize body reserves to meet energy requirements during gestation and lactation [3]. Adding fat to sow diets is one potential approach to ensure sows and piglets consume sufficient energy. Over the last two

\footnotetext{
* Correspondence: dongbing@cau.edu.cn

${ }^{1}$ State Key Laboratory of Animal Nutrition, College of Animal Science and Technology, China Agricultural University, Beijing 100193, China

Full list of author information is available at the end of the article
}

to three decades, many studies have evaluated effects of fat supplementation in diets on reproductive performance of sows and growth performance of piglets [4-32]. We conducted a systematic review to evaluate effects of fat supplementation in sow diets on sow reproductive performance and litter growth performance using these studies.

Effects of added fat on sows' reproductive performance and growth performance of offspring are inconsistent among studies because several factors such as genetics, nutritional supplementation, study parity of the sow, environmental temperatures, health status of sows and

(C) The Author(s). 2022 Open Access This article is licensed under a Creative Commons Attribution 4.0 International License, which permits use, sharing, adaptation, distribution and reproduction in any medium or format, as long as you give appropriate credit to the original author(s) and the source, provide a link to the Creative Commons licence, and indicate if changes were made. The images or other third party material in this article are included in the article's Creative Commons licence, unless indicated otherwise in a credit line to the material. If material is not included in the article's Creative Commons licence and your intended use is not permitted by statutory regulation or exceeds the permitted use, you will need to obtain permission directly from the copyright holder. To view a copy of this licence, visit http://creativecommons.org/licenses/by/4.0/ The Creative Commons Public Domain Dedication waiver (http://creativecommons.org/publicdomain/zero/1.0/) applies to the data made available in this article, unless otherwise stated in a credit line to the data. 
farm management likely influence results. Individual studies cannot standardize all these factors. To address this challenge, studies published from 1986 to 2020 that considered effects of dietary fat on sow feed intake, sow performance, and litter performance were retrieved. With these studies, we conducted a systematic review and meta-analysis to determine effects of dietary fat for sows. The aim of this review was to reveal the effects of added fat on sows and piglets across fat types, genetics, sow parities, dietary supplementation levels, and management systems. In total, 19 papers were included in the meta-analysis. This systematic review and analysis provide meaningful information to aid nutritionists and pig farmers effectively utilize dietary fat supplementation to improve sow performance and piglet growth.

\section{Materials and methods}

\section{Databases queried}

We searched ISI Web of Science, Science Direct, Scopus, ProQuest and Pubmed databases for publications related to use of dietary fat in sow diets. The following keywords or their combinations: high fat, high lipids, oil, dietary fat, sow and sows uncovered 29 papers [4-32] published from 1986 to 2020 .

\section{Criteria for study selection}

For a study to be included in the meta-analysis, all of the following criteria were satisfied. We screened these studies according to the following criteria:

1) The article was published in a peer-reviewed journal.

2) The study contained an un-supplemented treatment as a control and a fat supplemented group as a treatment(s).

3) The period of dietary fat supplementation occurred during late gestation (later than gestation day 85 ) to lactation or during lactation.

4) Supplementation levels of fat were at least equal to $2 \%(\mathrm{w} / \mathrm{w})$ in order to exhibit fat effect. The reason for the supplementation level is that according to National Research Council (NRC), background fat level without additional fat supplementation is approximately $2 \%$.

5) The author reported on at least one of the following response criteria: Average daily feed intake (ADFI) of sows during lactation, average daily energy intake (ADEI) of sows during lactation, litter weight at birth (Litter WT/birth), litter weight at weaning (Litter WT/ wean), litter average daily gain during lactation (Litter ADG), liveborn per litter (No. born alive), litter size at weaning (No. weaned), survival rate of piglets from birth to weaning (Survival rate), change in sow body weight during lactation (sow $\Delta-\mathrm{WT}$ ), change in sow backfat thickness during lactation (sow $\Delta-\mathrm{BF}$ ), wean to estrus interval of sows (sow WEI), and milk fat concentration (Milk fat).

In these 29 papers, dietary fat supplementation was less than $2 \%$ in five papers [22, 29-32], the fat supplementation period was not in late gestation or lactation in four papers [16, 21, 23, 25], and one article was not peer reviewed [26], which led to exclusion of five articles from the final review. Therefore, 19 papers were included in this systematic review and meta-analysis (Table 1).

\section{Definition \\ Study, treatment, and observation}

In this review, the term, "study", refers to a scientific article which involves one or more treatments. The term, "treatment", refers to a comparison of a treated group of sows fed supplemental fat and its corresponding unsupplemented control group of sows. One study can have several treatments, as long as a comparison between an un-supplemented control and a fat supplemented treatment exists. An observation refers to a measurable dependent response variable.

\section{ADFI and ADEI}

During late gestation, sows were fed a fixed amount of feed based on body weight or a target total energy intake. During lactation, sows were provided ad libitum access to feed. Thus, we analyzed ADFI and ADEI only during the lactation period (post farrowing to weaning). Most authors reported metabolizable energy (ME) concentration of diets except for two studies $[5,14]$ in which authors reported digestible energy (DE). As long as the control was an un-supplemented group, studies using both $\mathrm{ME}$ and $\mathrm{DE}$ were deemed valid.

\section{Litter ADG}

Litter ADG was either reported in the article, or calculated by subtracting litter weight at weaning from litter weight at birth (after cross-fostering) then divided by days of lactation.

\section{Piglet survival rate}

Piglet survival rate was either reported in the article, or calculated as number of piglets per litter at weaning divided by number of piglets per litter (after crossfostering) multiplied by $100 \%$.

\section{Changes of sow body weight and backfat thickness}

Change of sow body weight and backfat thickness was either reported in the article, or calculated by subtracting the sow body weight or backfat thickness at weaning from its body weight or backfat thickness at farrowing. Negative values indicate loss of body weight or backfat 


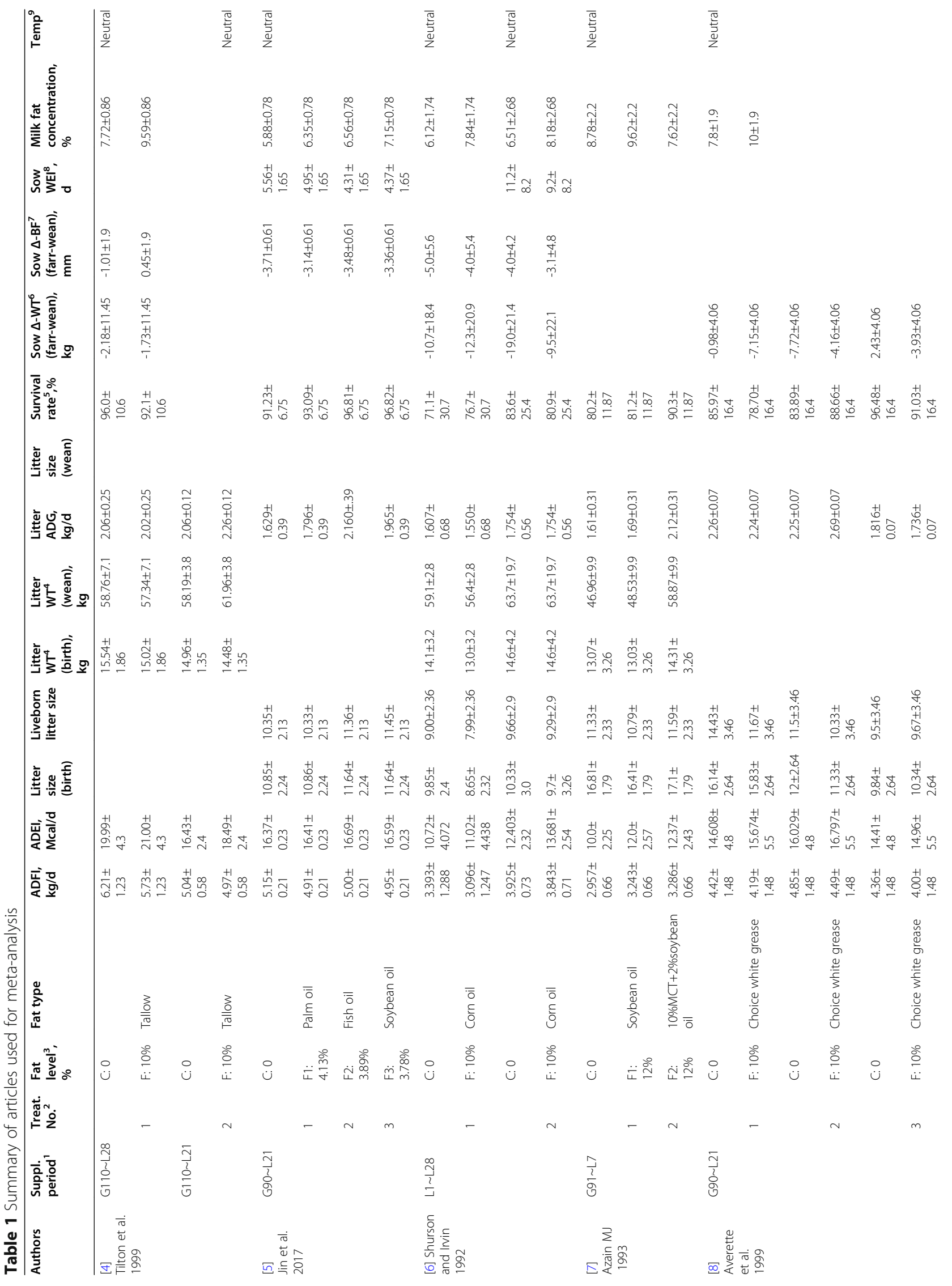




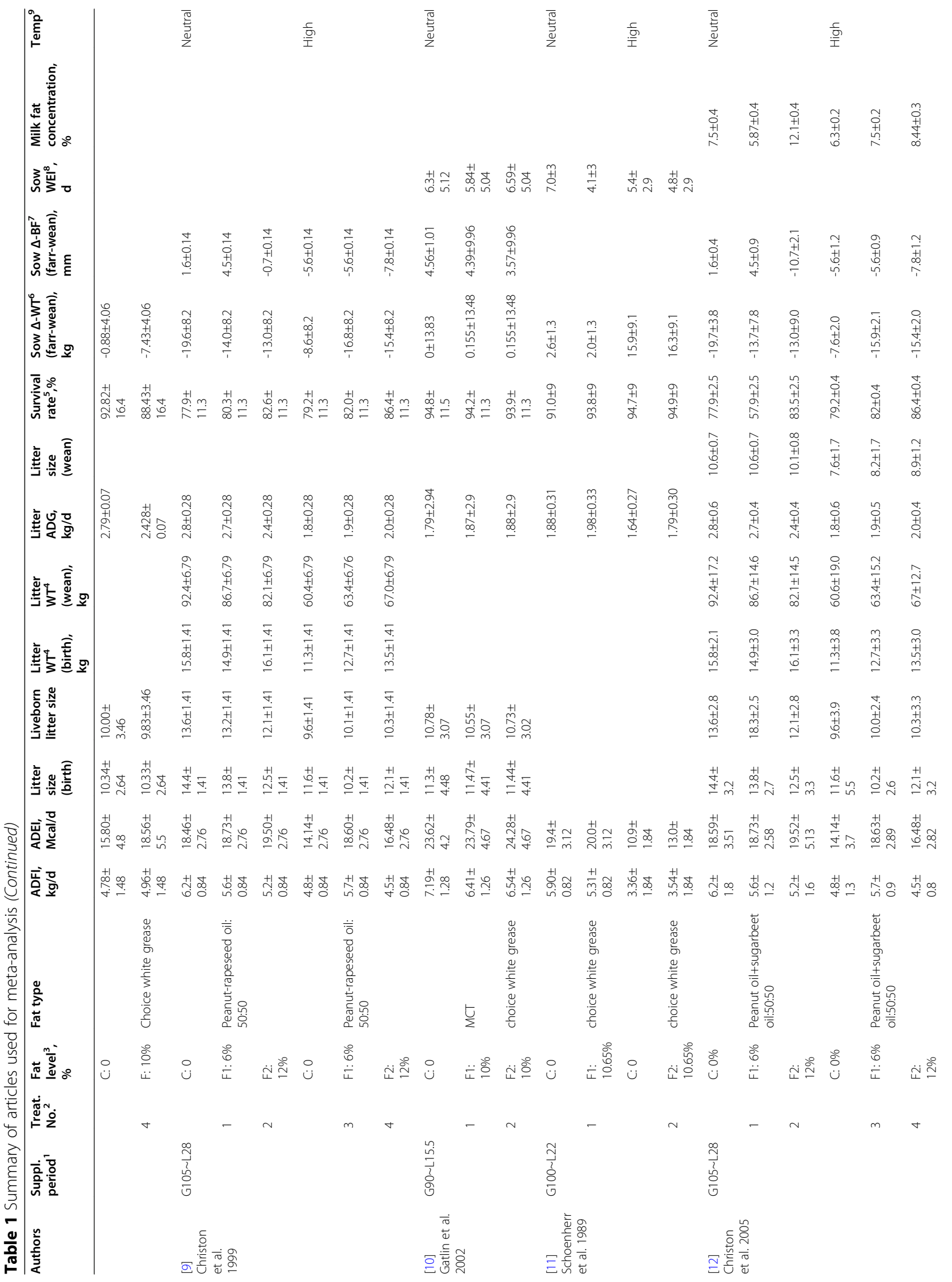




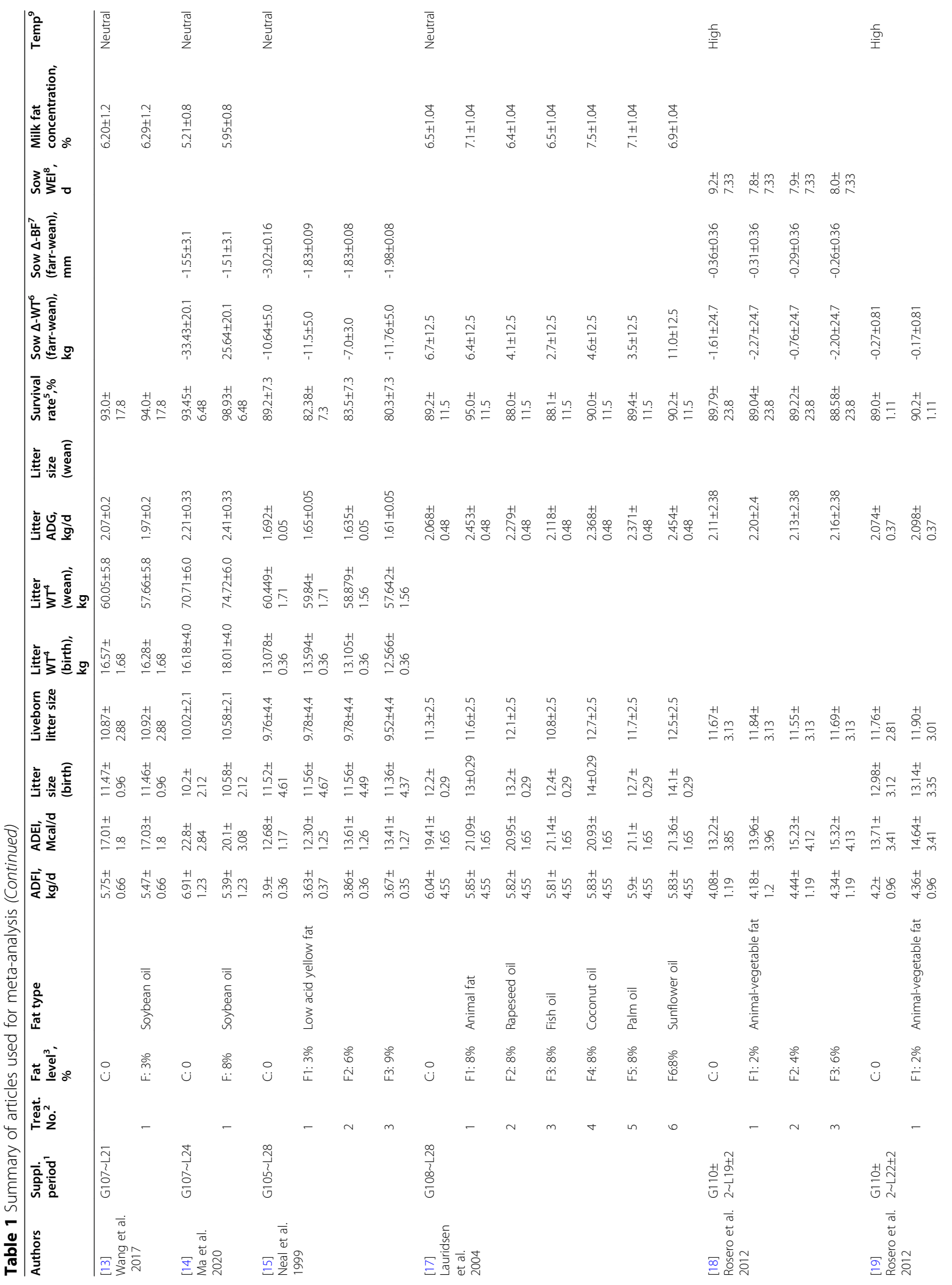




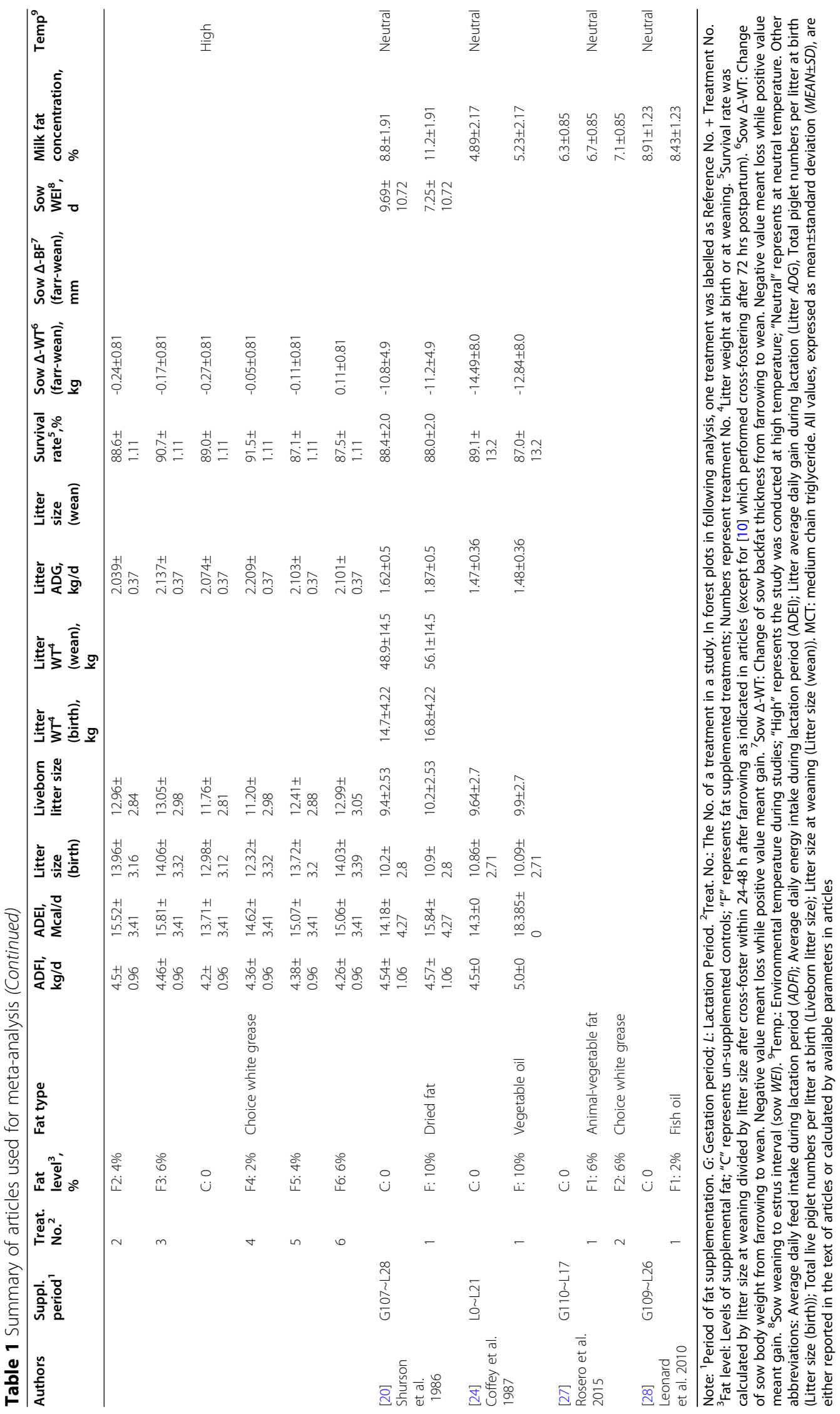


thickness during lactation while positive values indicate gain of body weight or backfat thickness.

\section{Milk fat concentration}

Milk fat concentration was defined as the percentage of fat in milk (\%, w/v). The milk samples were collected from d 7 to $d 21$ of lactation in these studies. Milk fat was determined by extraction with organic solvents [4, $9,20,24,26,27]$ or by an automated infrared filtration system $[17,25]$.

\section{Litter size}

Total born litter size includes number of live, stillborn, and mummified piglets. Liveborn per litter contains only number of live pigs at birth.

\section{Temperature}

When authors claimed that the studies were conducted at tropical environment or high temperature, these studies (treatments) were categorized as "High temperature". There were 5 studies $[9,11,12,18,19]$ categorized "high temperature". The studies of [9] and [12] described "high temperature (tropical environment)" by providing geographic location and season. The study of [11] provided a specific high temperature $\left(32{ }^{\circ} \mathrm{C}\right)$ versus a neutral temperature $\left(20^{\circ} \mathrm{C}\right)$. The studies of [18] and [19] were conducted in Oklahoma and reported tropical environmental temperatures at $33 \pm 5{ }^{\circ} \mathrm{C}$. The rest of the studies either did not clearly describe the temperatures during studies, or reported average temperature under $30{ }^{\circ} \mathrm{C}$.

\section{Statistical analysis}

In this study, $\mathrm{R}$ software version 4.1.0 ("Camp Pontanezen" Copyright (๑) 2021; The R Foundation for Statistical Computing) was used to analyze all studies using the meta package. Table 2 shows the code in $\mathrm{R}$ for this meta-analysis. The effects of dietary fat on sow performance and litter growth performance were determined by comparing the dietary fat treatment with the corresponding un-supplemented control. Before conducting meta-analysis, we tested heterogeneity among studies by calculating Cochran- $Q, I^{2}$ statistics, and chi-square test with significance set as $P<0.05$ and $I^{2}$ statistics with a

Table 2 R-code for meta-analysis of control and fat supplemented treatments

madata<-read.csv("F:/Meta/filename.csv",header = T)

library (meta)

m.res<-metacont (Ne,Me,Se,Nc,Mc,Sc,data=madata,studlab=paste (Reference),

comb.fixed=F,comb.random=T, method.tau="SJ",

hakn=T, sm="SMD")

m.res

forest(m.res, test.overall.random $=\mathrm{T}$ ) cut-off of $50 \%$ that defined statistical significance of heterogeneity. Due to the apparent heterogeneity among included studies, we chose a random-effects model for the meta-analysis. Forest plots were used for overall assessment of the meta-analysis. Probability values ( $P$ values) less than or equal to 0.10 were deemed significant and $P$ values over 0.10 but less than 0.15 were considered a trend.

To further investigate the potential factors such as temperature and supplementation level on the fat effect, we analyzed the study data through subgroup analysis. For example, when we analyzed ADFI, ADEI, litter ADG, Numbers of alive piglets at birth, Survival rate and sow body weight loss during lactation, we divided the studies into two subgroups according to the reported environmental temperature (high temperature or neutral temperature) because the observations in these variables were sufficient for statistical analysis compared to the rest variables. For analysis of other variables such as Milk fat concentration and WEI, we attempted to divide the data according to other factors, such as supplementation levels of fat, genetic lines, oil type, parities, but the numbers of the observations were not sufficient for a statistical analysis. Forest plots were used to demonstrate the fat effect on individual response variables.

\section{Results \\ ADFI of sows}

Authors of 16 papers (46 treatments) reported ADFI of sows was affected by adding fat in diets (1603 observations in un-supplemented control; 1609 observations in fat treatment). The standardized mean difference (SMD; "Difference" used in following text) between control and fat treatment was $-0.14 \mathrm{~kg} / \mathrm{d}(P=0.04)$ (Fig. $1 \mathrm{~A})$, which means that inclusion of fat in diets decreased ADFI of sows. Further analysis (Supplemental Fig. 1) proved the relationship between fat levels and difference of ADFI.

Some authors reported increased ADFI due to fat supplementation at high temperature which was defined in Materials \& Methods $[9,11,12,18,19]$. The treatments in these studies were recognized as high temperature treatments because authors claimed these studies were conducted in tropical environments. Consequently, we divided our studies into conducting at high temperature (14 treatments; 636 observations in control and 629 observations in fat treatment) and those conducting at neutral temperature (32 treatments; 967 observations in control and 980 observations in fat treatment). Fat inclusion decreased sows' ADFI by $0.31 \mathrm{~kg} / \mathrm{d}(P<0.01)$ at neutral temperature (Fig. 1B). In contrast, high temperature conditions, dietary fat supplementation increased ADFI by $0.23 \mathrm{~kg} / \mathrm{d}(P<0.01$; Fig. $1 \mathrm{C})$. 


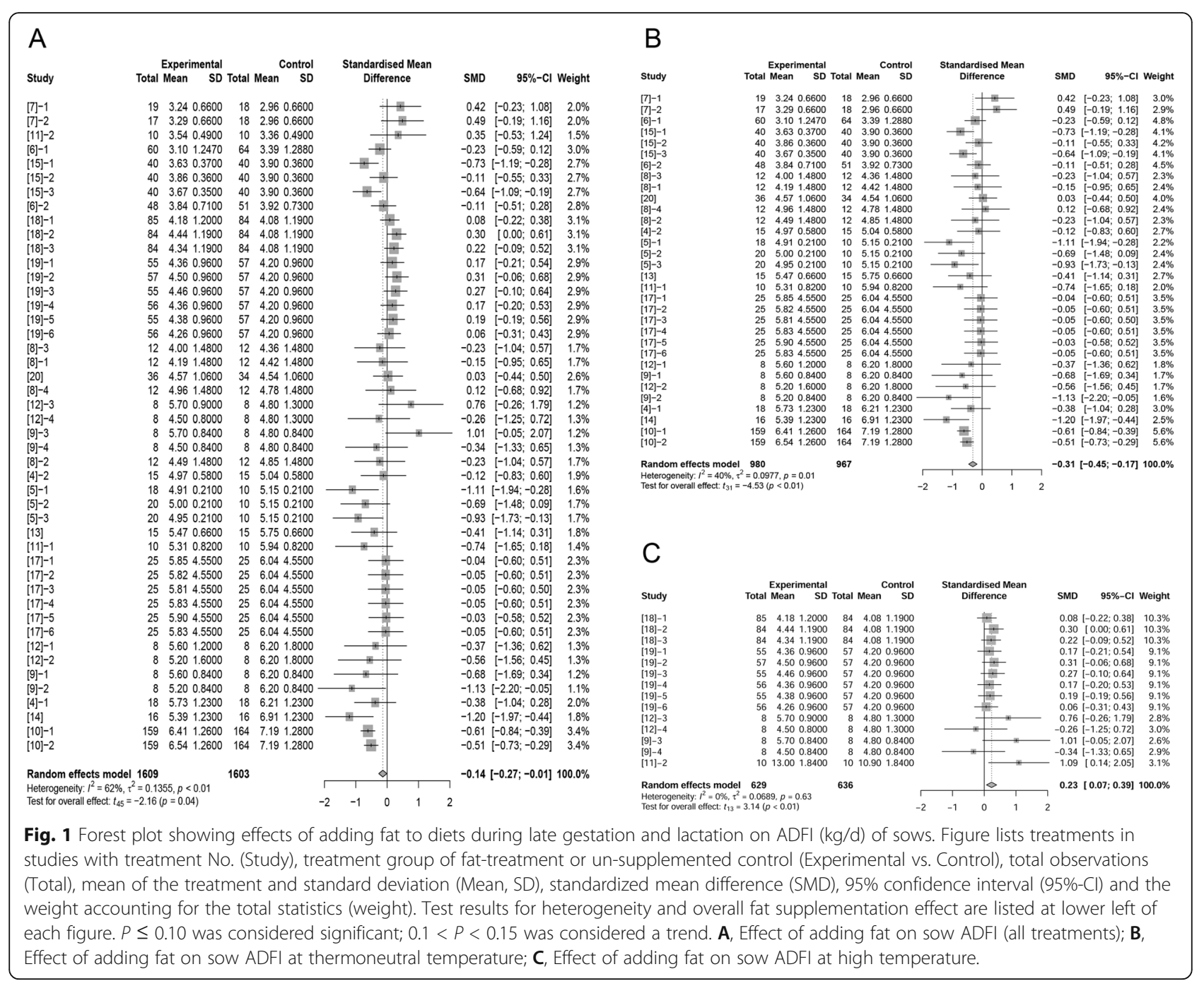

\section{ADEl of sows}

We further analyzed effects of fat inclusion on sows' ADEI (Fig. 2 A, B, C). There were 19 papers (45 treatments) with 1569 observations in control and 1573 observations in fat treatment that reported fat effect on ADEI. The difference of ADEI between unsupplemented control and fat treatment was not statistically significant with a trend of increased ADEI of 0.11 $\mathrm{Mcal} / \mathrm{d}(P=0.11$, Fig. $2 \mathrm{~A})$. When considering only studies conducted under neutral temperature conditions, ADEI was not different between control and fat treatments $(P=0.58$, Fig. $2 \mathrm{~B})$. At high temperatures, fat supplementation increased ADEI by $0.4 \mathrm{Mcal} / \mathrm{d}$ with a $95 \%$ confidence interval $(95 \%-\mathrm{CI})$ of 0.19 to $0.60 \mathrm{Mcal} / \mathrm{d}(P=$ 0.0012 , Fig. 2C). Further analysis proved that fat addition with different levels decreased ADFI but tended to increase ADEI (Supplemental Fig. 1).

\section{Litter size and litter weight}

Nine papers (19 treatments) reported litter weights (428 observations in control and 423 observations in fat treatment). There were no significant differences between control and fat treatment on litter weights at birth $(P=$ 0.40 ; Fig. $3 \mathrm{~A})$ or at weaning $(P=0.46$; Fig. $3 \mathrm{~B})$. Based on total litter weight at birth of the controls, we sorted data from lightest to heaviest. We analyzed the effects of fat supplementation on litter birth weight of the lightest $33 \%$ of litters. Fat supplementation tended to improve litter birth weight by $0.24 \mathrm{~kg}(P=0.14)$ when litters were lighter than average at birth (Fig. 3C).

Litter weight was related closely to litter size, so we examined the effects of supplemental fat on litter size (Fig. 4A, B). Authors of 15 papers (39 treatments) reported number of total piglets (including mummies, stillborns and born alive) per litter at birth (1220 


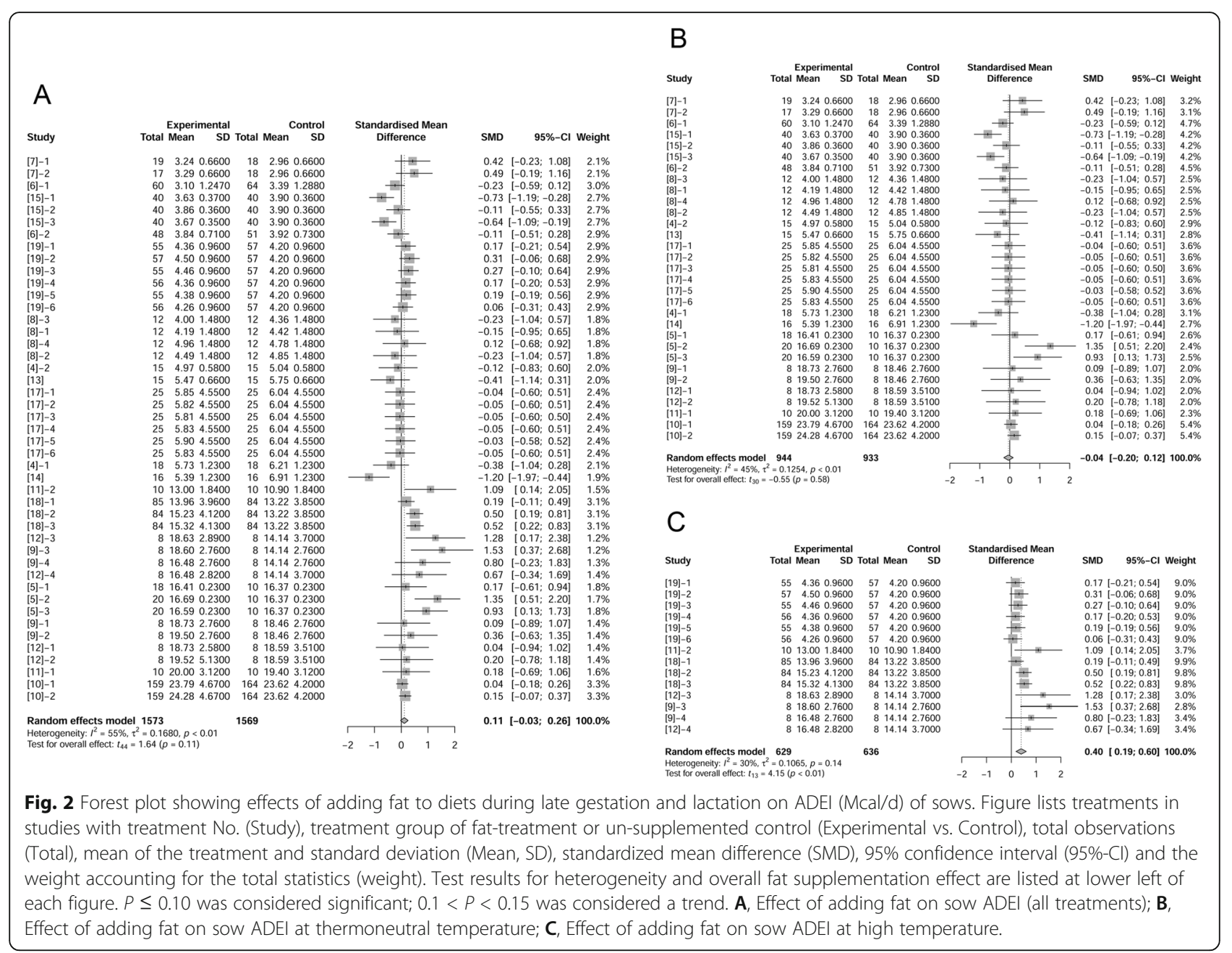

observations in control and 1231 observations in fat treatment). The difference between control and fat treatment was 0.45 piglets per litter $(P=0.07$, Fig. 4 A) which showed a positive effect of fat on total number of piglets at birth. Regression analysis on fat level and increased ME indicated a positive relationship (Supplemental Fig. 2). Environmental temperature may influence effects of fat on litter size, so we removed treatments at high temperature and re-analyzed the data. The difference between control and fat treatment at neutral temperature was $0.60(P=0.07$, Fig. $4 \mathrm{~B})$. At high temperature, fat supplementation did not significantly change litter size at birth (data not shown).

However, when the number of liveborn per litter was analyzed in this review, fat supplementation showed no effect $(P=0.90)$ when comparing 1442 observations in control and 1482 observations in fat treatment (Fig. 5A). We confirm no significant effect of fat on liveborn per litter $(P=0.36$, Fig. $5 \mathrm{~B})$ at neutral temperature, while at high temperature, fat supplementation had positive effect (increased 0.15 pigs per litter) on liveborn per litter
$(P=0.03$; Fig. $5 C)$. The above analysis revealed that fat supplementation increased total number of piglets per litter at birth but had no significant effect on liveborn litter size.

To confirm the effect of fat on liveborn per litter, we further divided 29 treatments at neutral temperature into 2 categories: < $10 \%$ supplemental fat and $\geq 10 \%$ supplemental fat. When the fat level was $\geq 10 \%$, fat decreased the liveborn per litter $(P=0.10$; Fig. 5D). It demonstrated multiple functions of added fat on liveborn per litter: it increased the liveborn per litter at high temperature, but decreased it at neutral temperatures only if the supplementation level of fat was $\geq 10 \%$.

\section{Litter ADG}

We analyzed 17 papers (47 treatments) to evaluate effects of supplemental fat on litter growth performance from birth to weaning using 1614 observations in control and 1620 observations in fat-supplemented treatments. Daily weight gain of litters was not different between control and fat treatments $(P=1.00$; Fig. 6A). 


\begin{tabular}{|c|c|c|c|c|}
\hline \multirow[b]{2}{*}{ Study } & \multicolumn{2}{|c|}{ Experimental } & \\
\hline & Total Mean & SD & otal Mean & \\
\hline$[12]-3$ & 612.70 & 3.3000 & $\begin{array}{ll}6 & 11.30\end{array}$ & \\
\hline [12]-4 & $\begin{array}{ll}6 & 13.50\end{array}$ & 3.0000 & $\begin{array}{ll}6 & 11.30\end{array}$ & 3.8000 \\
\hline$[9]-3$ & 812.70 & 1.4100 & $\begin{array}{lll}8 & 11.30\end{array}$ & 1.4100 \\
\hline$[9]-4$ & 813.50 & 1.4100 & 811.30 & 1.4100 \\
\hline [7]-1 & 1913.03 & 3.2600 & 1813.07 & \\
\hline$[7]-2$ & 1714.31 & 3.2600 & 1813.07 & \\
\hline$[15]-1$ & $\begin{array}{ll}40 & 13.59\end{array}$ & 1.5600 & $\begin{array}{ll}40 & 13.08\end{array}$ & 0.3600 \\
\hline$[15]-2$ & $\begin{array}{ll}40 & 13.11\end{array}$ & 1.5600 & $\begin{array}{ll}40 & 13.08\end{array}$ & 0.3600 \\
\hline [15]-3 & 4012.57 & 1.5600 & 4013.08 & 0.3600 \\
\hline$[6]-1$ & $\begin{array}{lll}60 & 13.00\end{array}$ & 3.2000 & $64 \quad 14.10$ & 3.2000 \\
\hline$[6]-2$ & $48 \quad 14.60$ & 4.2000 & 5114.60 & 4.2000 \\
\hline [20] & 3616.80 & 4.2200 & $34 \quad 14.70$ & \\
\hline [4]-2 & 1814.48 & 1.3500 & $18 \quad 14.96$ & 1.3500 \\
\hline [4]-1 & 1815.02 & 1.8600 & $18 \quad 75.54$ & 1.860 \\
\hline ?]- & 614.90 & 3.0000 & 615.80 & \\
\hline & $\begin{array}{ll}6 & 16.10\end{array}$ & 3.3000 & $\begin{array}{ll}6 & 15.80\end{array}$ & \\
\hline- & $\begin{array}{lll}8 & 14.90\end{array}$ & 1.4100 & $\begin{array}{ll}8 & 15.80\end{array}$ & \\
\hline & 816.10 & 1.4100 & 815.80 & \\
\hline [14] & 1618.01 & 4.0000 & $16 \quad 16.18$ & 4.000 \\
\hline [13] & 1516.28 & 1.6800 & 1516.57 & 1.6800 \\
\hline
\end{tabular}

Random effects model 423

428

Heterogeneity: $l^{2}=42 \%, \tau^{2}=0.1394, p=0.03$

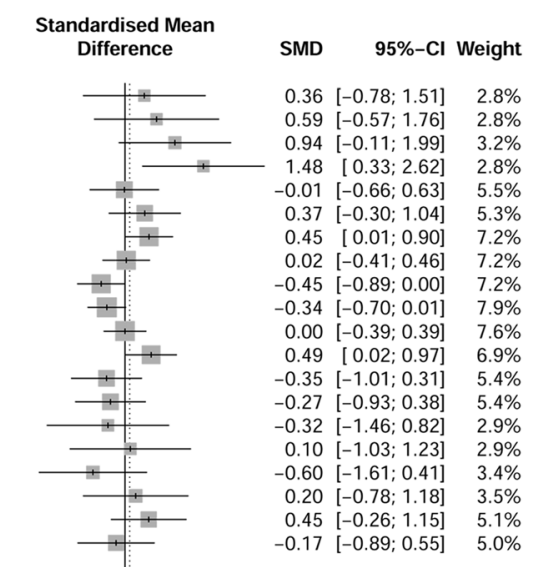

Test for overall effect: $t_{19}=0.86(p=0.40)$

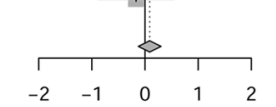

$0.09[-0.13 ; 0.30] 100.0 \%$

B

\begin{tabular}{|c|c|c|c|c|c|c|c|c|}
\hline \multirow{3}{*}{ Study } & \multicolumn{3}{|c|}{ Experimental } & \multirow{2}{*}{$\begin{array}{r}\text { Control } \\
\text { SD }\end{array}$} & \multirow{2}{*}{$\begin{array}{l}\text { Standardised Mean } \\
\text { Difference }\end{array}$} & \multirow[b]{2}{*}{ SMD } & \multirow{2}{*}{\multicolumn{2}{|c|}{ 95\%-CI Weight }} \\
\hline & Total Mean & SD & otal Mean & & & & & \\
\hline & 1948.53 & 9.9000 & 1846.96 & & 11 & 0.16 & {$[-0.49 ; 0.80]$} & $5.5 \%$ \\
\hline [7]-2 & 1758.87 & 9.9000 & 1846.96 & 9.9000 & & 1.18 & {$[0.45 ; 1.90]$} & $5.2 \%$ \\
\hline [20] & 3656.10 & 14.5000 & 3448.90 & 14.5000 & + & 0.49 & {$[0.01 ; 0.97]$} & $6.0 \%$ \\
\hline [4]-2 & 1561.96 & 3.8000 & 1558.19 & 3.8000 & $\longrightarrow$ & 0.97 & {$[0.20 ; 1.73]$} & $5.1 \%$ \\
\hline [4]-1 & 1857.34 & 7.1000 & 1858.76 & 7.1000 & - & -0.20 & {$[-0.85 ; 0.46]$} & $5.5 \%$ \\
\hline$[6]-1$ & 6056.40 & 2.8000 & 6459.10 & 2.8000 & & -0.96[ & {$[-1.33 ;-0.59]$} & $6.2 \%$ \\
\hline [13] & 1557.66 & 5.8000 & 1560.05 & 5.8000 & I: & -0.40 & {$[-1.12 ; 0.32]$} & $5.2 \%$ \\
\hline [12]-4 & 667.00 & 12.7000 & 660.40 & 19.0000 & F & 0.38 & {$[-0.77 ; 1.52]$} & $4.0 \%$ \\
\hline$[9]-3$ & 663.40 & 5.8800 & 660.40 & 5.8800 & + & 0.47 & {$[-0.68 ; 1.63]$} & $4.0 \%$ \\
\hline$[9]-4$ & 667.00 & 5.8800 & 660.40 & 5.8800 & 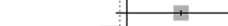 & 1.04 & {$[-0.20 ; 2.28]$} & $3.7 \%$ \\
\hline [15]-1 & 4059.84 & 1.7100 & 4060.45 & 1.7100 & $r:$ & -0.35 & {$[-0.79 ; 0.09]$} & $6.0 \%$ \\
\hline [15]-2 & 4058.88 & 1.5600 & 4060.45 & 1.7100 & & -0.95[ & {$[-1.41 ;-0.49]$} & $6.0 \%$ \\
\hline [15]-3 & 4057.64 & 1.5600 & 4060.45 & 1.7100 & $\div$ & -1.70[ & {$[-2.21 ;-1.18]$} & $5.9 \%$ \\
\hline [12]-3 & 663.40 & 15.2000 & 660.60 & 19.0000 & \pm & 0.15 & {$[-0.98 ; 1.28]$} & $4.0 \%$ \\
\hline$[6]-2$ & 4863.70 & 19.6000 & 5163.70 & 19.7000 & & 0.00 & {$[-0.39: 0.39]$} & $6.2 \%$ \\
\hline 14 & 1674.72 & 6.0000 & 1670.71 & 6.0000 & 1 & 0.65 & {$[-0.06 ; 1.37]$} & $5.3 \%$ \\
\hline [12]-1 & 686.70 & 14.6000 & 692.40 & 17.2000 & & -0.33 & {$[-1.47 ; 0.81]$} & $4.0 \%$ \\
\hline [12]-2 & 682.10 & 14.5000 & 692.40 & 17.2000 & - & -0.60 & {$[-1.77 ; 0.57]$} & $3.9 \%$ \\
\hline [9]- & 886.70 & 6.7900 & 892.40 & 6.7900 & 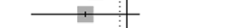 & -0.79 & {$[-1.82 ; 0.24]$} & $4.3 \%$ \\
\hline$[9]-2$ & 882.10 & 6.7900 & 892.40 & 6.7900 & $\mp$ & -1.43[ & {$[-2.57 ;-0.30]$} & $4.0 \%$ \\
\hline & & & 421 & & $\infty$ & -0.14 & {$[-0.51 ; 0.2$} & $0.0 \%$ \\
\hline $\begin{array}{l}\text { Hetero } \\
\text { Test fol }\end{array}$ & $\begin{array}{l}0.5124, p<C \\
.75(p=0.46\end{array}$ & & & & -2 & & & \\
\hline
\end{tabular}
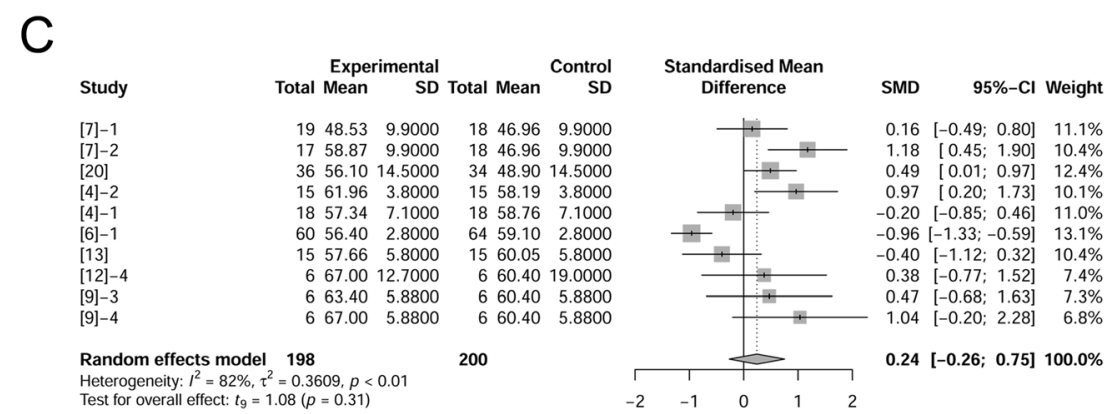

Fig. 3 Forest plot showing effects of adding fat to diets during late gestation and lactation on litter weight (kg). Figure lists treatments in studies with treatment No. (Study), treatment group of fat-treatment or un-supplemented control (Experimental vs. Control), total observations (Total), mean of the treatment and standard deviation (Mean, SD), standardized mean difference (SMD), 95\% confidence interval (95\%-Cl) and the weight accounting for the total statistics (weight). Test results for heterogeneity and overall fat supplementation effect are listed at lower left of each figure. $P \leq 0.10$ was considered significant; $0.1<P<0.15$ was considered a trend. A, Effect of adding fat on litter weight (at birth); B, Effect of adding fat on litter weight (at wean); C, Effect of adding fat on smaller litter weight than average (at birth). 


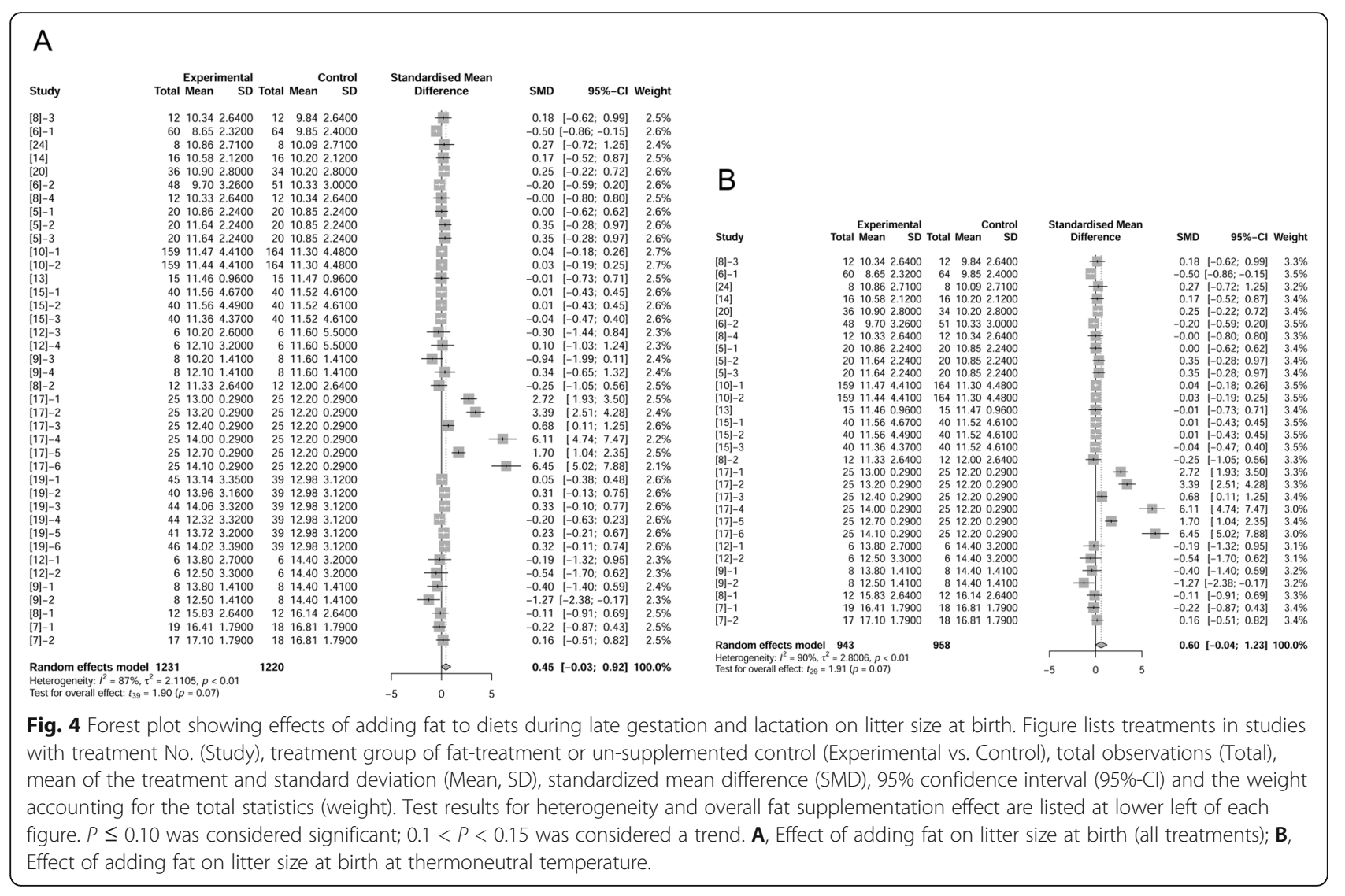

Likewise, levels of fat supplementation $(<10 \%$ or $\geq 10 \%)$ had no effect on litter ADG (data not shown).

We then segmented these treatments into two subgroups regardless the level of fat inclusion according to environmental temperature with 1265 observations in high temperature group (636 in control; 629 in fat treatment) and 1969 observations in neutral temperature group (978 in control; 991 in fat treatment). In high temperature, adding fat improved litter ADG from birth to weaning by $0.10 \mathrm{~kg} / \mathrm{d}(95 \%-\mathrm{CI}: 0.01$ to $0.19 \mathrm{~kg} / \mathrm{d}, P=$ 0.03; Fig. 6B). But in neutral temperatures, adding fat displayed no significant effect $(P=0.71$; Fig. $6 C)$.

\section{Survival rate to weaning}

We analyzed survival rate of piglets from birth to weaning. Authors of 17 papers ( 45 treatments) reported survival rate of piglets (1595 observations in control and 1601 observations in fat treatment). We observed no significant difference between control and fat treatments $(P$ $=0.48$, Fig. 7A). Previous researchers reported that fat can improve survival rate in herd with low piglet survival [33]. We thus examined effects in studies that reported piglet survival less than $80 \%$ in the controls (Fig. 7B). No significant differences were observed between control and fat supplementation treatments $(P=0.40)$. Likewise, piglet survival was not affected when considering the level of fat supplementation (2\%, $4 \%$ and $10 \%$; data not shown). In our dataset, fat supplementation in sow diets had no effect on piglet survival rate from birth to weaning.

\section{Milk fat concentration}

Authors of 13 papers (25 treatments) reported fat concentration in milk. Milk was sampled from d 3 to 21 postpartum. There were 307 observations in control and 310 observations in fat treatment. Dietary fat supplementation increased the milk fat concentration by $1.06 \%$ $(P=0.03$, Fig. 8A) compared to the control at all temperatures. When we removed 2 treatments which were conducted at high temperature and showed positive effects, the remaining 23 treatments (291 observations in control and 294 observations in fat treatment) still demonstrated increased milk fat concentration by $0.66 \%$ as a result of adding fat $(P=0.08$, Fig. $8 \mathrm{~B})$.

\section{Losses of body weight and backfat thickness}

Dietary fat in sow diets resulted in reducing body weight loss and backfat loss during lactation $[8,9,12,15]$. But according to our analysis based on 39 treatments (1515 observations in control and 1493 observations in fat treatment) for body weight change and 22 treatments (943 observations in control and 955 observations in fat 


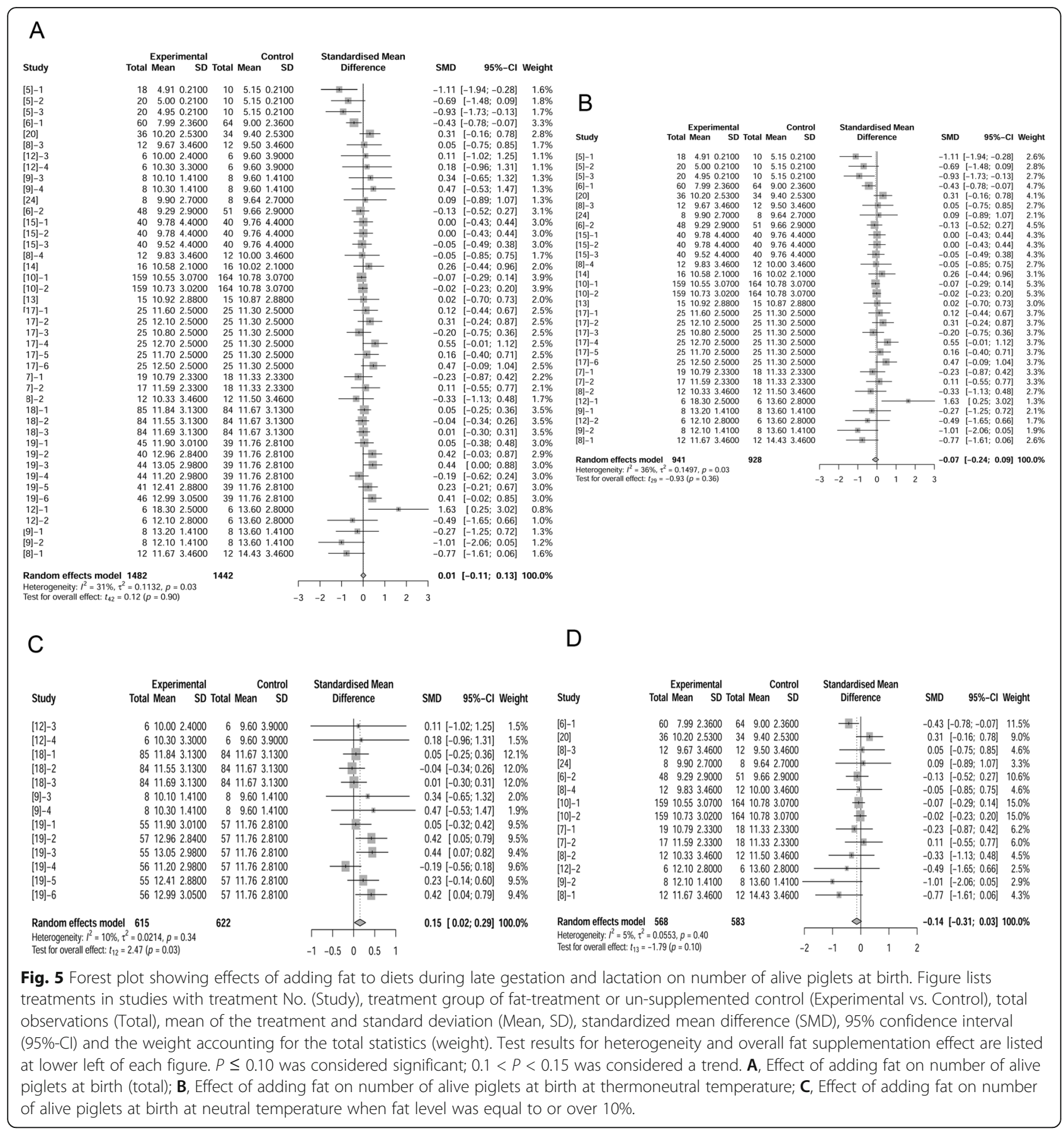

treatment) for backfat thickness change, no significant effects of supplemented dietary fat were present $(P=$ 0.67 and $P=0.66$ respectively, Fig. $9 \mathrm{~A}, \mathrm{~B}$ ) by adding fat in diets. We extracted treatments where control sows lost more than $7.72 \mathrm{~kg}$ throughout lactation. These sows represented about $36 \%$ of the dataset with the greatest weight loss. In these higher weight-loss sows, fat supplementation tended to reduce lactational body weight loss by $0.38 \mathrm{~kg}(P=0.11$, Fig. $9 \mathrm{C})$. However, loss of backfat thickness was not influenced by fat supplementation in these sows (data not shown).

\section{Wean to estrus interval (WEI)}

Wean to estrus interval was reported in 6 papers (11 treatments) and included 685 observations in control and 704 observations in fat treatment. Fat supplementation shortened WEI by $0.20 \mathrm{~d}(P=0.01$, Fig. 10$)$.

Collectively, the literature discussed in this review indicated that fat supplementation can be beneficial for 


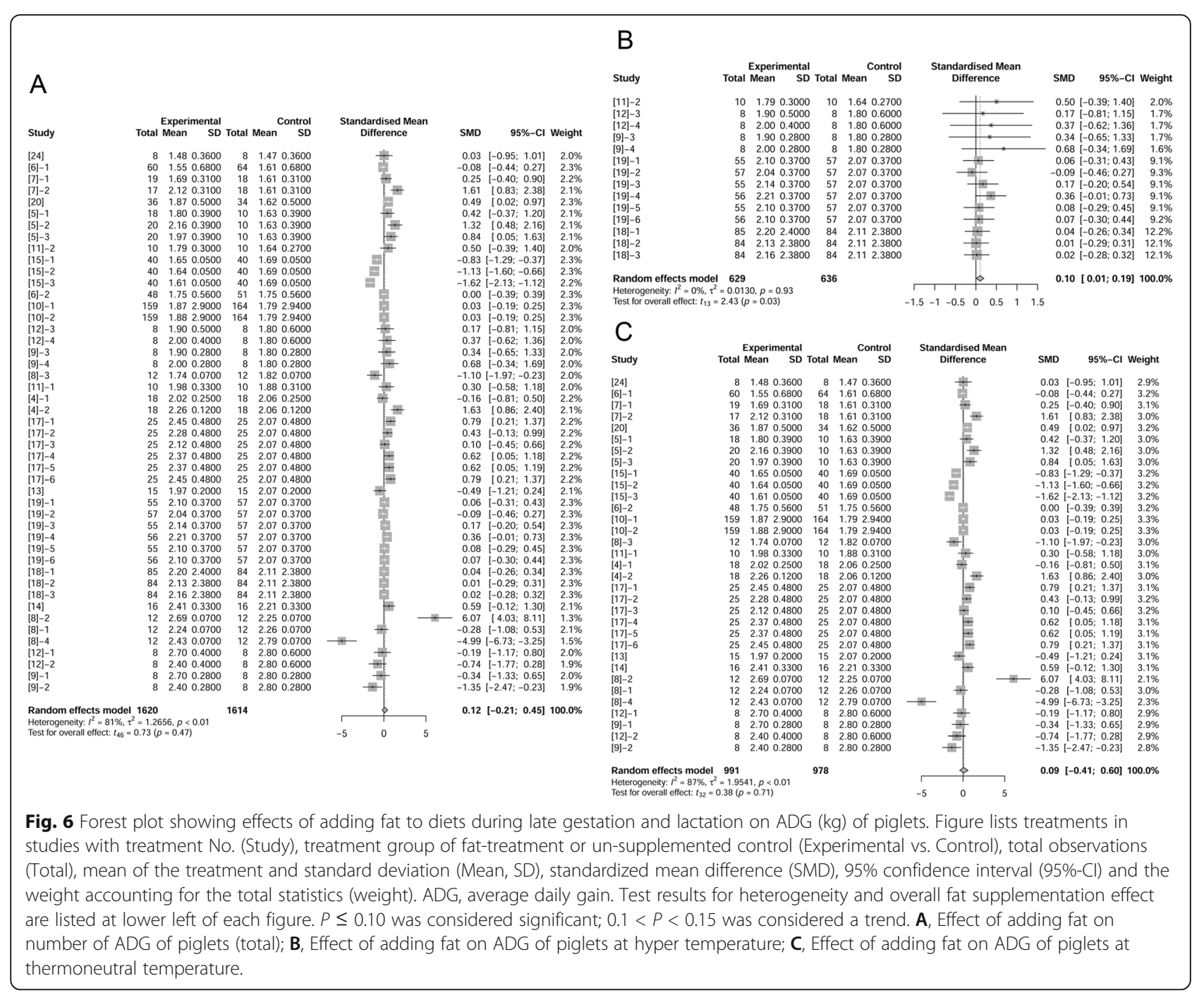

sow reproductive performance and litter growth performance (Table 3). Fat supplementation in sow diets during late gestation through lactation period decreased ADFI $(P<0.05)$ and tended to increase ADEI $(P=0.11)$. Litter weights at birth $(P=0.40)$ or weaning $(P=0.46)$ were not influenced by fat supplementation. Added fat increased total numbers of piglets at birth $(P=0.07)$, but had no effect on liveborn per litter $(P=0.90)$ or survival rate $(P=0.48)$ of piglets to weaning. Fat supplementation had no effect on reducing loss of sow body weight $(P=0.67)$ or backfat thickness $(P=0.66)$, but did increase milk fat concentration $(P=0.03)$ and shorten WEI $(P=0.01)$. In some circumstances, fat supplementation had specific effects: it had a trend on improving the growth performance of piglets with light litter weights at birth $(P=0.14)$, or when the sows lost large body weight during lactation $(P=0.11)$. When the level of supplemented fat was $10 \%$ or greater, liveborn per litter decreased $(P=0.10)$ at neutral temperature.

\section{Discussion}

Sows lose significant amounts of energy during lactation. Increased body weight loss has become a greater problem in sows with larger litters [34, 35]. A recent comparison demonstrated that porcine fetuses are 40\% heavier and milk yield increased by 4 folds between 1935 and 2010 [36]. Sufficient dietary energy intake of sows can endorse the energy supply to piglets via milk and energy storage for subsequent estrus cycles. Thus, the primary purpose of adding fat to sows' diets is to increase energy intake of sows by increasing energy density of the diet. In this review, fat supplementation consistently reduced ADFI and tended to increase ADEI between control and fat-fed sows. Regulation of appetite and the resulting feed intake is an integrated scenario of several factors including the ingested nutrients and hormones $[37,38]$.

Ingestion of nutrients triggers release of a series of hormones from gastrointestinal tract. In pigs, these 


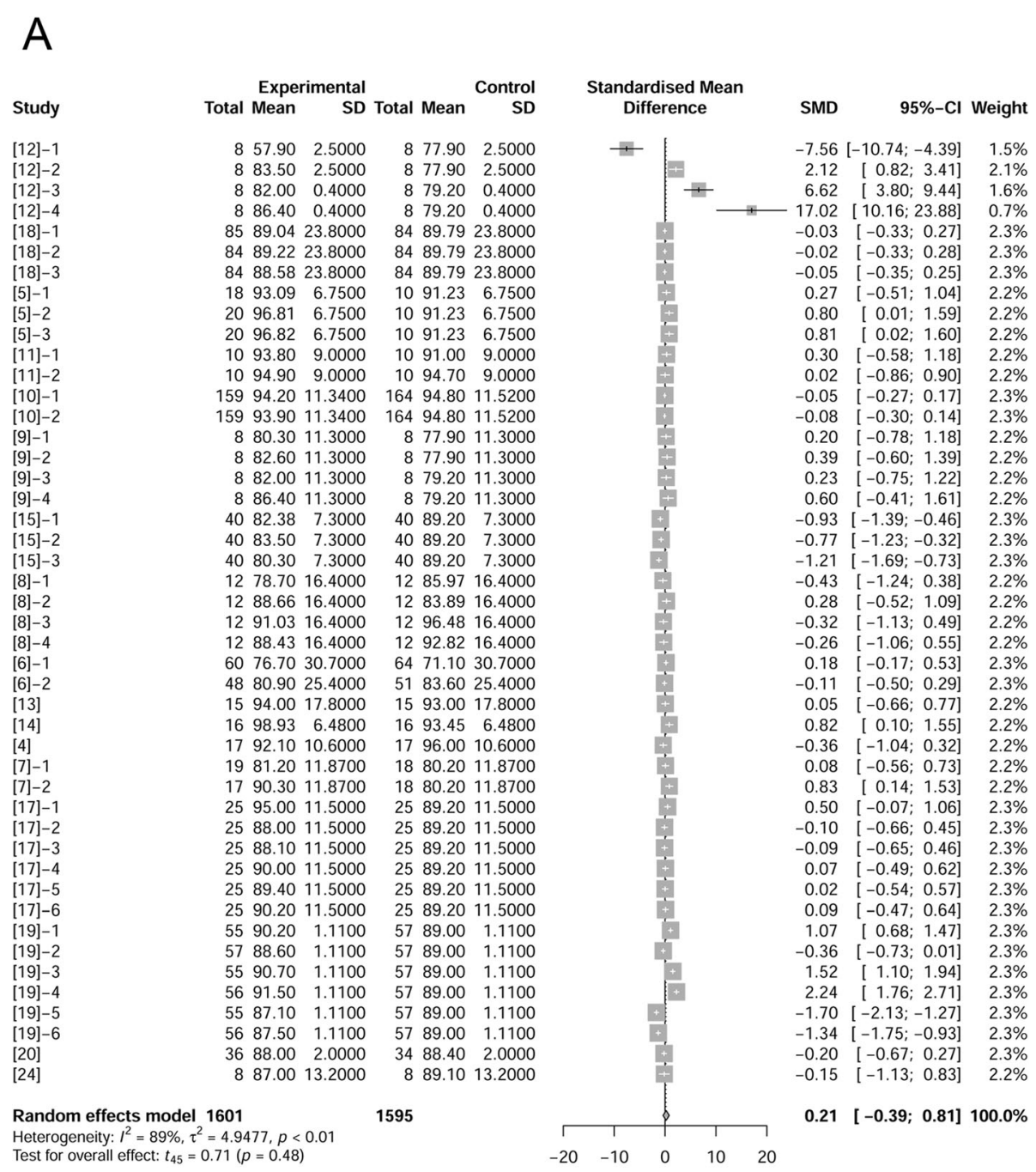

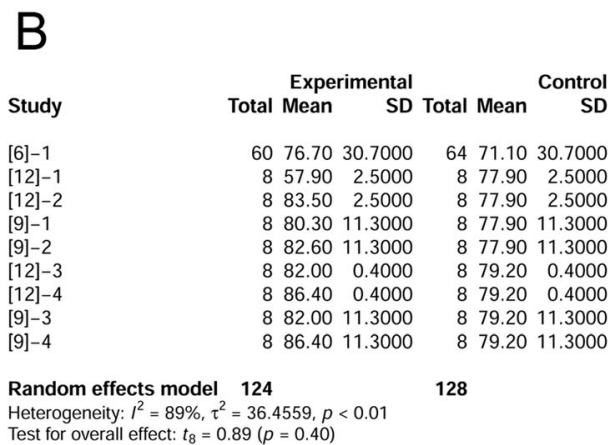

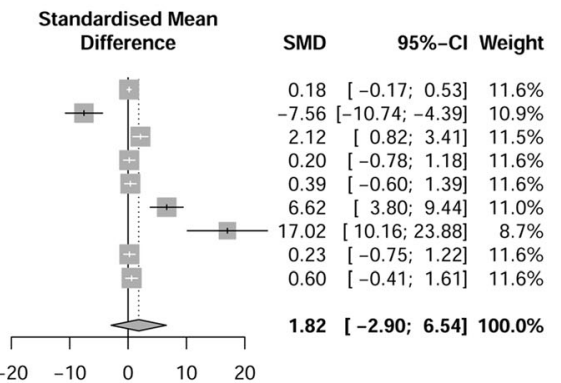

Fig. 7 Forest plot showing effects of adding fat to diets during late gestation and lactation on survival rate (\%) of piglets from birth to weaning. Figure lists treatments in studies with treatment No. (Study), treatment group of fat-treatment or un-supplemented control (Experimental vs. Control), total observations (Total), mean of the treatment and standard deviation (Mean, SD), standardized mean difference (SMD), 95\% confidence interval $(95 \%-\mathrm{Cl})$ and the weight accounting for the total statistics (weight). ADG, average daily gain. Test results for heterogeneity and overall fat supplementation effect are listed at lower left of each figure. $P \leq 0.10$ was considered significant; $0.1<P<0.15$ was considered a trend. A, Effect of adding fat on number of survival rate of piglets (total); $\mathbf{B}$, Effect of adding fat in sow diets on survival rate of piglets when survival rates were less than $80 \%$. 


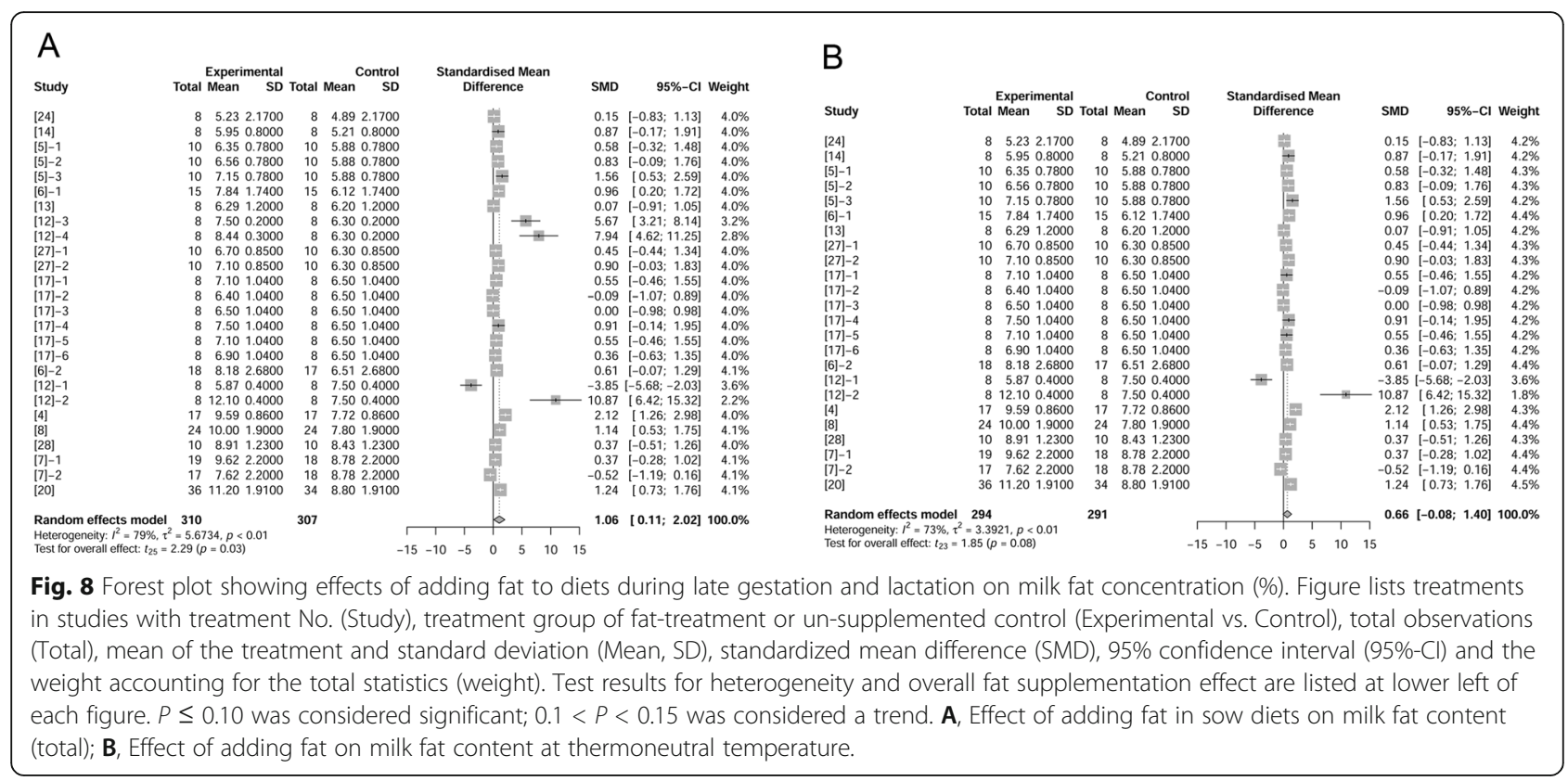

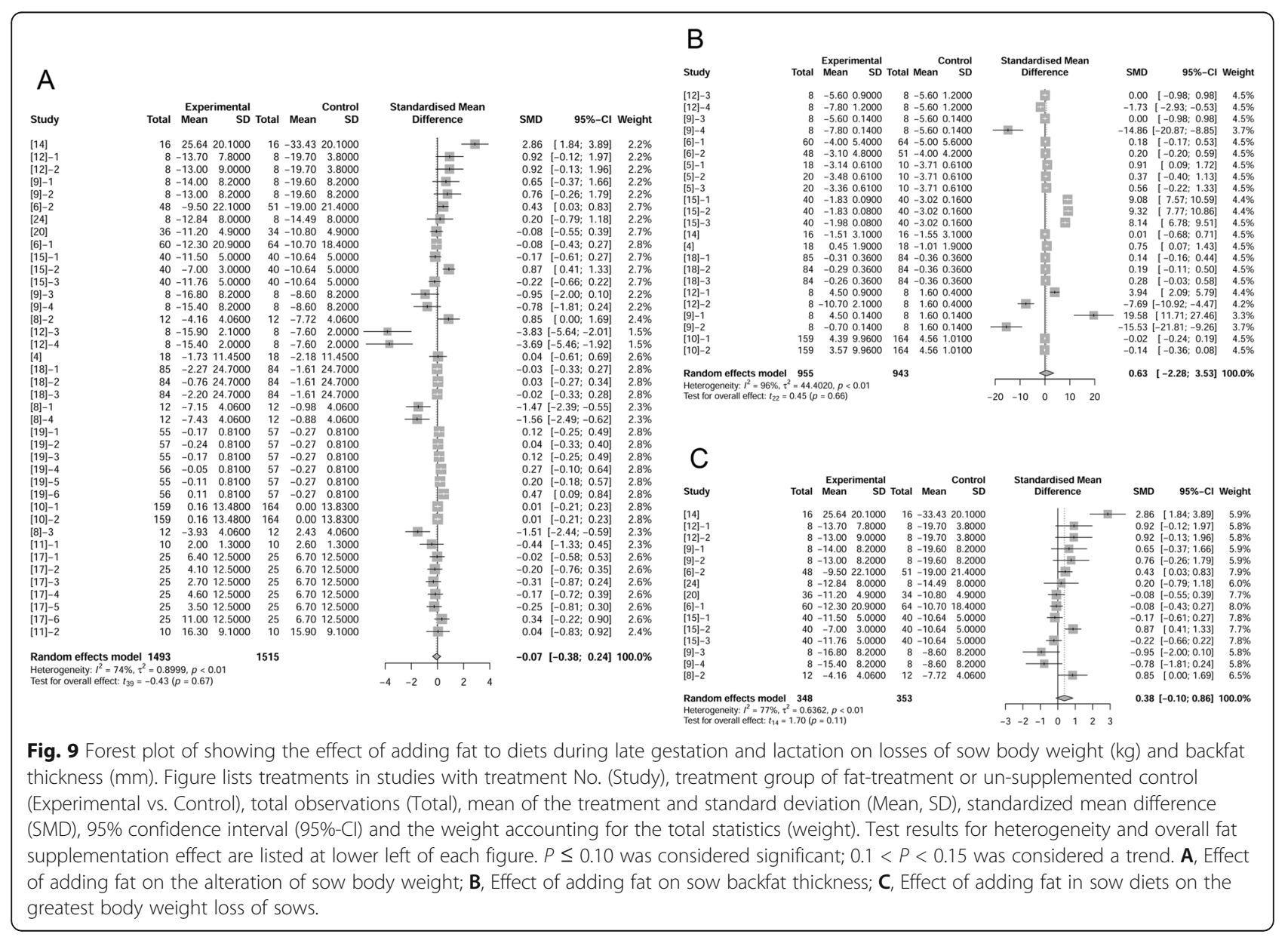




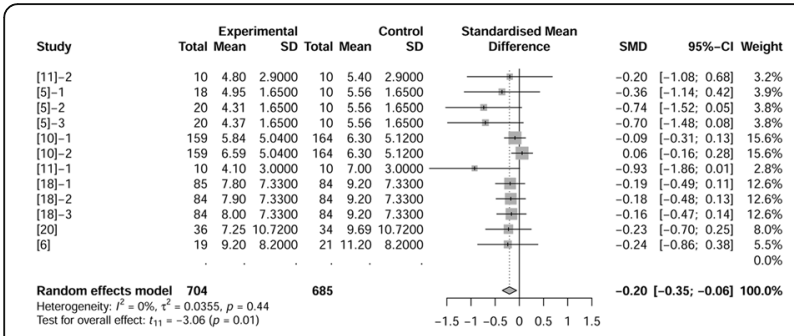

Fig. 10 Forest plot showing effects of adding fat to diets during late gestation and lactation on WEI (d) of sows. Figure lists treatments in studies with treatment No. (Study), treatment group of fat-treatment or un-supplemented control (Experimental vs. Control), total observations (Total), mean of the treatment and standard deviation (Mean, SD), standardized mean difference (SMD), 95\% confidence interval $(95 \%-\mathrm{Cl})$ and the weight accounting for the total statistics (weight). WEl, wean to estrus interval. Test results for heterogeneity and overall fat supplementation effect are listed at lower left of each figure. $P \leq 0.10$ was considered significant; $0.1<P<0.15$ was considered a trend.

hormones are mainly cholecystokinin (CCK), glucagon like peptide-1 (GLP-1), peptide tyrosine tyrosine (PYY) and ghrelin [39]. CCK, GL and PYY elicit satiation of food. A high-fat meal can effectively induce secretion of these satiety hormones compared to high-starch diets [40]. In addition, previous studies reported that pigs fed with high fat diets resulted in changes in regulatory

Table 3 Overall effects of adding fat to sow diets on performance of sows and piglets ${ }^{1}$

\begin{tabular}{lllll}
\hline Criterion & Source $^{2}$ & SMD $^{3}$ & 95\%-Cl & P-value $^{\mathbf{5}}$ \\
\hline ADFl, kg/d & Fig.1A & -0.14 & $-0.27 ;-0.01$ & 0.04 \\
ADEl, Mcal/d & Fig.2A & 0.11 & $-0.03 ; 0.26$ & 0.11 \\
Litter weight (birth), kg & Fig.3A & 0.09 & $-0.13 ; 0.30$ & 0.40 \\
Litter weight (weaning), kg & Fig.3B & -0.14 & $-0.51 ; 0.24$ & 0.46 \\
Litter size (birth) & Fig.4A & 0.45 & $-0.03 ; 0.92$ & 0.07 \\
Liveborn litter size & Fig.5A & 0.01 & $-0.11 ; 0.13$ & 0.90 \\
Litter-ADG, kg/d & Fig.6A & 0.12 & $-0.21 ; 0.45$ & 0.47 \\
Weaning survival rate, \% & Fig.7A & 0.21 & $-0.39 ; 0.81$ & 0.48 \\
Milk Fat, \% & Fig.8A & 1.06 & $0.11 ; 2.02$ & 0.03 \\
Sow BW Loss, kg & Fig.9A & -0.07 & $-0.38 ; 0.24$ & 0.67 \\
Sow BF Loss, mm & Fig.9B & 0.63 & $-2.28 ; 3.53$ & 0.66 \\
Sow WEl, d & Fig.10 & -0.20 & $-0.35 ;-0.06$ & 0.01 \\
\hline
\end{tabular}

Note: ${ }^{1}$ Overall effects of adding fat to sow diets on performance of sows and piglets. ${ }^{2}$ Position of the figures where the relevant indicator data in the same row. ${ }^{3}$ SMD: Standardized mean difference. ${ }^{4} 95 \%$-Cl: $95 \%$ confidence interval. ${ }^{5} P$-value: Probability values less than or equal to 0.10 were deemed significant and $P$ values over 0.10 but less than 0.15 were considered a trend. Abbreviations: ADFI: Average daily feed intake during lactation period; ADEl: Average daily energy intake during lactation period; Litter weight (birth): Litter weight of piglets at birth; Litter weight (weaning): Litter weight of piglets at weaning; Litter size (birth): Total piglet numbers per litter at birth; Liveborn litter size: Total live piglet numbers per litter at birth; Litter-ADG: Litter average daily gain during lactation; Sow BW Loss: Loss of body weight loss of sows from farrowing to wean; Sow BF Loss: Loss of backfat thickness of sows from farrowing to wean; Sow WEl: Weaning to estrus interval of sows neuropeptides in the hypothalamus and alterations mostly in the dopaminergic system in the ventral hippocampus [41]. Ghrelin is unique among gastrointestinal hormones because it is a hunger signal. Ghrelin can be suppressed by ingested food especially food with high caloric density [42]. Carbon chain length and saturation of fatty acids impacts the effect of dietary fat on appetite and releasing of satiety hormones [43-47]. Fatty acids with longer carbon chain lengths had stronger effects on stimulation of appetite compared to shorter chain lengths of carbons (e.g., C16 > C10). The effect of polyunsaturated fatty acids was higher than that of monosaturated fatty acids. Hormones involved in regulation of feed intake integrate with plasma glucose, insulin, intestinal osmolality and enteric neurons to maintain a balance of energy intake and energy homeostasis in the body [48]. In lactating sows, adipocyte produced leptin contributed to the regulation of feed intake. Serum leptin levels were positively correlated with backfat thickness [49]. Previous studies have reported that serum leptin levels decreased by day 7 of lactation [50] and reached its lowest point during peak lactation [51]. Therefore, serum leptin may only play an important role in early lactation. Circulating leptin, luteinizing hormone concentrations and feed consumption during lactation are influenced by dietary energy intake during lactation in sows [52].

Under tropical temperatures, fat supplementation of diets increased feed intake and consequently increased energy intake according to our analysis. The additional fat intake increased the liveborn per litter and piglet growth during lactation. There were not enough observations to analyze how the additional fat intake affects changes of body weight, backfat thickness and WEI in sows at tropical environment. Higher feed intake of sows under heat stress may be due to a lower heat increment of fat compared to other nutrients [53]. Our analysis verified that fat supplementation was beneficial for sow feed intake, energy intake, and piglet growth performance under the condition of heat stress.

Fat contains 2.25 times more energy per unit of weight than carbohydrates. Vegetable oils are higher in ME than animal fats [54]. Dietary fat elicits several positive effects including improved palatability [55], reduced feed consumption, and improved feed efficiency [56]. Dietary starch supplementation in lactating primiparous sows functions in protein deposition in piglets while dietary fat is used preferentially for milk fat synthesis at a high feeding level [57].

Moreover, more than as an energy source, fat plays an important role in promoting reproductive functions. Other researchers demonstrated that sows fed with fat supplemented diet had higher piglet survival rate, increased growth rate and shorter postweaning interval to 
estrus than those sows fed with iso-energetic diets that relied on starch to provide metabolizable energy [58, 59]. In the present summary, fat supplementation clearly shortened WEI. Fat has long been deemed as a nutritional and metabolic regulator of reproduction in sows (reviewed in [60]). In women, mice, and rats, diets enriched with fat increased ovarian steroids (estradiol and progesterone) in circulation [61-63]. Thus, fat is likely involved in the induction of post weaning ovulation and shortening of WEI.

Ovulation is closely related to body energy intake and is controlled by the hypothalamus-pituitary-ovarian axis. There are two theories explaining the correlation between energy balance and reproduction. One is the metabolic fuel hypothesis which proposes nutrient molecules and metabolites can be oxidized and act as sensory stimuli for the responses of reproductive axis [64]. The other theory proposes that fat's promoted effect on the production of estrogen production and sex hormone binding globulin. Fat supplementation improves the production of estrogen and sex hormone binding globulin, and these products can elevate the sensibility of hypothalamic-pituitary-ovarian axis [65]. The preservation of reproductive function relies on a certain amount of adiposity [66]. Therefore, fat can act as both metabolic fuel and adipose preservation to regulate reproductive functions.

According to the analysis in this article, fat supplementation did not change losses of body weight and backfat thickness during lactation. Milk fat concentration was increased by adding fat to the sow's diet but piglet ADG was not improved.

One of the reasons that increased concentration of milk fat didn't increase ADG of piglets was likely due to the reliance on cross-fostering rather than insufficient digestion of milk fat by piglets. Around $98 \%$ of commercial pig farms use cross-fostering as a management technique for creating litters with more uniform body weight [67]. Cross-fostering should be performed as early as possible, usually from 12 to $24 \mathrm{~h}$ after farrowing when the teat order is not established [68]. Cross culture is usually adjusted within a treatment. Researchers reported that neonatal piglets had a much higher capacity to absorb fat than milk provided [69], which greatly exceeded the output capacity of sow mammary gland. Different cross-fostering strategies could affect the growth performance of litters. For example, litter growth performance was decreased if piglets with lighter birth weights were cross fostered with heavier piglets, or new born piglets with heavier body weights suckled middle and posterior teats [70], or cross foster conducted later than 48 h. after farrowing that caused higher plasma cortisol [71]. Litter composition, cross foster time point, body weight variation of litter and access to creep feed are all variables for determination of piglet ADG.
We expected piglet survival rate from birth to weaning to be improved especially since adding fat increased colostral fat content $[14,72]$, which was critical for new born survival [73]. Likewise, we found no significant effect of fat on piglet survival rate in studies that reported survival rates lower than $80 \%$. Pettigrew and Moser reviewed studies during 1974 to 1979 and found that adding fat to sow diets improved piglet survival rate in herds with lower than $80 \%$ [33]. If the piglet survival rate was above $80 \%$, fat supplementation had little effect on improving survival rate. In the current article, collected studies from 1986 through 2020. During two to three decades since Pettigrew and Moser's report in 1991, sows have undergone a series of genetic selection, and pig farm facilities and management have greatly improved. Overall survival rates in studies summarized for our analysis ranged from $71.10 \%$ to $96.48 \%$. Only $17 \%$ of studies reported survival rates below $80 \%$ in our collection. With survival rate at such a high level, sows were not responsive to dietary fat such that survival rate was not affected.

In modern era, sow prolificacy results in larger litters but it also increases the proportion of piglets born with low body weights [70]. Adding fat in sow diets further increased the litter size but the total litter weight at birth was not changed, neither was liveborn per litter, which suggested increased incidence of stillborn, mummied, and dead piglets at birth.

The conclusions drawn in this paper were derived from the overall analysis of 19 papers rather than an individual study. Under a specific circumstance, types of oil/fat (digestible energy of a specific fat, ratio of unsaturated to saturated fatty acids, carbon chain length [74]), environmental temperature, supplementation level of fat, parity of sows and management strategy can all impact on the effect of fat supplementation. Additional, new functions of dietary fat could be revealed by metaanalysis with more studies in the future.

\section{Conclusions}

We reviewed 19 papers published from 1986 to 2020 and determined that compared to un-supplemented controls, adding fat in sow diets during late gestation and lactation decreased ADFI $(P<0.05)$ and tended to increase ADEI $(P=0.11)$. Fat supplementation had no effect on litter weights at birth $(P=0.40)$ or weaning $(P=$ 0.46). Total numbers of piglets per litter at birth were increased by fat supplementation $(P=0.07)$, but we observed no effects on liveborn per litter $(P=0.90)$ or survival rate $(P=0.48)$ of piglets to weaning. Fat supplementation had no effect on sow body weight loss $(P=$ $0.67)$ or backfat thickness changes $(P=0.66)$, but increased milk fat concentration $(P=0.03)$ and shorten WEI $(P=0.01)$. In specific circumstances, fat 
supplementation tended to improve growth performance of piglets with low litter weights at birth $(P=0.14)$, or when sows lost large amounts of body weight during lactation $(P=0.11)$. When the level of supplemented fat was $10 \%$ or higher, it decreased the liveborn per litter $(P$ $=0.10)$ at neutral temperature. It can be concluded that during late gestation and lactation, the strategic use of fat could be beneficial for sow reproductive performance and litter growth performance.

\section{Abbreviations}

ADEl: Average daily energy intake; ADFI: Average daily feed intake;

ADG: Average daily gain; CCK: Cholecystokinin; Cl: Confidence interval; DE: Digestible energy; GLP-1: Glucagon like peptide-1; ME: Metabolizable energy; SMD: Standardized mean difference; PYY: Peptide tyrosine tyrosine; WEl: Wean to estrus interval

\section{Supplementary Information}

The online version contains supplementary material available at https://doi. org/10.1186/s40104-021-00662-3.

Additional file 1. Relationship between fat level and SMD. A, Fat level and SMD of ADFI (Fat treatment vs. un-supplemented control), kg/d; B, Fat level and SMD of ADEl (fat treatment vs. un-supplemented control), Mcal/d. SMD: Standardised mean of difference. Diameters of bubbles represented weighing of SMD.

Additional file 2. Regression analysis on the level of fat supplementation and increased ME (Mcal). X axis: Level of added fat; $Y$ axis: Difference of ME of diets between added fat and un-supplemented control (Mcal). R linear repression (Pearson's) was performed. The regression equation was: 4.89 * Fat level-0.01614=Difference of ME R-squared= 0.7792 .

\section{Acknowledgements}

Not applicable.

\section{Authors' contributions}

LW and BD design and wrote the manuscript. $J$ and $C L$ critically edited the concentration and text. LW, JY and BD finalized the manuscript. The authors read and approved the final manuscript.

\section{Funding}

This study is funded by The National Key Research and Development Program of China (2016YFD0700201).

\section{Availability of data and materials}

Not applicable.

\section{Declarations}

Ethics approval and consent to participate

Not applicable.

\section{Consent for publication}

Not applicable.

\section{Competing interests}

The authors declare that they have no competing interests.

\section{Author details}

${ }^{1}$ State Key Laboratory of Animal Nutrition, College of Animal Science and Technology, China Agricultural University, Beijing 100193, China. ${ }^{2}$ West Central Research and Outreach Center, University of Minnesota, Morris, MN 56267, USA. ${ }^{3}$ Department of Animal Science, College of Agriculture and Biological Sciences, South Dakota State University, Brookings, SD 57007, USA.
Received: 8 August 2021 Accepted: 2 December 2021

Published online: 08 February 2022

\section{References}

1. Tokach MD, Menegat MB, Gourley KM, Goodband RD. Review: Nutrient requirements of the modern high-producing lactating sow, with an emphasis on amino acid requirements. Animal. 2019;13:2967-77. https://doi. org/10.1017/S1751731119001253.

2. Rosero DS, Boyd RD, McCulley M, Odle J, Van Heugten E. Essential fatty acid supplementation during lactation is required to maximize the subsequent reproductive performance of the modern sow. Anim Reprod Sci. 2016;168: 151-63. https://doi.org/10.1016/j.anireprosci.2016.03.010.

3. Walsh MC, Geraert PA, Maillard R, Kluess J, Lawlor PG. The effect of a nonstarch polysaccharide-hydrolysing enzyme (Rovabio(R) Excel) on feed intake and body condition of sows during lactation and on progeny growth performance. Animal. 2012;6:1627-33. https://doi.org/10.1017/S1751731112 000237

4. Tilton SL, Miller PS, Lewis AJ, Reese DE, Ermer PM. Addition of fat to the diets of lactating sows: I. Effects on milk production and composition and carcass composition of the litter at weaning. J Anim Sci. 1999;77:2491-500. https://doi.org/10.2527/1999.7792491X.

5. Jin C, Fang Z, Lin Y, Che L, Wu C, Xu S, et al. Influence of dietary fat source on sow and litter performance, colostrum and milk fatty acid profile in late gestation and lactation. J Anim Sci. 2017;88:1768-78. https://doi.org/1 0.1111 /asj.12836.

6. Shurson GC, Irvin KM. Effects of genetic line and supplemental dietary fat on lactation performance of Duroc and Landrace sows. J Anim Sci. 1992;70: 2942-9. https://doi.org/10.2527/1992.70102942x.

7. Azain MJ. Effects of adding medium-chain triglycerides to sow diets during late gestation and early lactation on litter performance. J Anim Sci. 1993;71: 3011-9. https://doi.org/10.2527/1993.71113011x.

8. Averette LA, Odle J, Monaco MH, Donovan SM. Dietary fat during pregnancy and lactation increases milk fat and insulin-like growth factor I concentrations and improves neonatal growth rates in swine. J Nutr. 1999; 129:2123-9. https://doi.org/10.1093/jn/129.12.2123.

9. Christon R, Saminadin G, Lionet H, Racon B. Dietary fat and climate alter food intake, performance of lactating sows and their litters and fatty acid composition of milk. Anim Sci. 1999;69:353-65. https://doi.org/10.1017/s13 $5772980005092 x$.

10. Gatlin LA, Odle J, Soede J, Hansent JA. Dietary medium- or long-chain triglycerides improve body condition of lean-genotype sows and increase suckling pig growth. J Anim Sci. 2002;80:38-44. https://doi.org/10.2527/2 002.80138x.

11. Schoenherr WD, Stahly TS, Cromwell GL. The effects of dietary fat or fiber addition on energy and nitrogen digestibility in lactating, primiparous sows housed in a warm or hot environment. J Anim Sci. 1989;67:473-81. https:// doi.org/10.2527/jas1989.672473x.

12. Christon $R$, Lionet $H$, Racon B, Saminadin G, Gaudru L, Schaeffer B, et al. The effect of dietary fat level on feed intake and performances of lactating sows and their litters. Biotechnol Anim Husb. 2005;21:195-204. https://doi.org/1 0.2298/BAH0506195C.

13. Wang CQ, Bai YS, Zhao X, Shi BM, Meng XY, Shan AS. Effects of feeding sodium stearoyl-2-lactylate diets to lactating sows on performance, digestibility of nutrients, composition, and fat globule size in milk. J Anim Sci. 2017;95:5091-9. https://doi.org/10.2527/jas2017.1851.

14. Ma C, Liu Y, Liu S, Levesque CL, Zhao F, Yin J, et al. Branched chain amino acids alter fatty acid profile in colostrum of sows fed a high fat diet. J Anim Sci Biotechnol. 2020;11:9. https://doi.org/10.1186/s40104-019-0423-9.

15. Neal SM, Irvin KM, Shurson GC, Harris B, Hatfield EE. Effect of lactation diet fat Level on sow and litter performance. Prof Anim Sci. 1999;15:7-13 10. 15232/s1080-7446(15)31716-2.

16. Peng $X$, Yan C, Hu L, Liu Y, Xu Q, Wang R, et al. Effects of fat supplementation during gestation on reproductive performance, milk composition of sows and intestinal development of their offspring. Animals (Basel). 2019;9:125. https://doi.org/10.3390/ani9040125.

17. Lauridsen C, Danielsen V. Lactational dietary fat levels and sources influence milk composition and performance of sows and their progeny. Livest Prod Sci. 2004;91:95-105. https://doi.org/10.1016/j.livprodsci.2004.07.014.

18. Rosero DS, van Heugten E, Odle J, Cabrera R, Arellano C, Boyd RD. Sow and litter response to supplemental dietary fat in lactation diets during high 
ambient temperatures. J Anim Sci. 2012;90:550-9. https://doi.org/10.2527/ja s.2011-4049.

19. Rosero DS, Van Heugten E, Odle J, Arellano C, Boyd RD. Response of the modern lactating sow and progeny to source and level of supplemental dietary fat during high ambient temperatures. J Anim Sci. 2012;90:2609-19. https://doi.org/10.2527/jas.2012-4242.

20. Shurson GC, Hogberg MG, DeFever N, Radecki SV, Miller ER. Effects of adding fat to the sow lactation diet on lactation and rebreeding performance. J Anim Sci. 1986;62:672-80. https://doi.org/10.2527/jas1986. 623672x.

21. Laws J, Laws A, Lean IJ, Dodds PF, Clarke L. Growth and development of offspring following supplementation of sow diets with oil during mid to late gestation. Animal. 2007;1:1490-6. https://doi.org/10.1017/S17517311 07000699 .

22. Rooke JA, Sinclair AG, Edwards SA, Cordoba R, Pkiyach S, Penny PC, et al. The effect of feeding salmon oil to sows throughout pregnancy on preweaning mortality of piglets. Anim Sci. 2001;73:489-500. https://doi.org/10.1 017/s135772980005846x.

23. Petrone RC, Williams KA, Estienne MJ. Effects of dietary menhaden oil on growth and reproduction in gilts farrowed by sows that consumed diets containing menhaden oil during gestation and lactation. Animal. 2019;13: 1944-51. https://doi.org/10.1017/S1751731119000193.

24. Coffey MT, Yates JA, Combs GE. Effects of feeding sows fat or fructose during late gestation and lactation. J Anim Sci. 1987;65:1249-56. https://doi. org/10.2527/jas1987.6551249x.

25. Laws J, Amusquivar E, Laws A, Herrera E, Lean IJ, Dodds PF, et al. Supplementation of sow diets with oil during gestation: Sow body condition, milk yield and milk composition. Livest Sci. 2009;123:88-96. https://doi.org/10.1016/.livsci.2008.10.012.

26. Tapia R, Santiago D. Nutritional value of dietary lipids in lactating sow diets, in Animal Sci \& Poultry Sci. Raleigh: Graduate Faculty of North Carolina State University; 2014

27. Rosero DS, Odle J, Mendoza SM, Boyd RD, Fellner V, Van Heugten E. Impact of dietary lipids on sow milk composition and balance of essential fatty acids during lactation in prolific sows. J Anim Sci. 2015;93:2935-47. https:// doi.org/10.2527/jas.2014-8529.

28. Leonard SG, Sweeney T, Bahar B, Lynch BP, O'Doherty JV. Effect of maternal fish oil and seaweed extract supplementation on colostrum and milk composition, humoral immune response, and performance of suckled piglets. J Anim Sci. 2010;88:2988-97. https://doi.org/10.2527/jas.2009-2764.

29. Ariza-Nieto C, Bandrick M, Baidoo SK, Anil L, Molitor TW, Hathaway MR. Effect of dietary supplementation of oregano essential oils to sows on colostrum and milk composition, growth pattern and immune status of suckling pigs. J Anim Sci. 2011;89:1079-89. https://doi.org/10.2527/jas.2010-3 514.

30. Rooke JA, Sinclair AG, Edwards SA. Feeding tuna oil to the sow at different times during pregnancy has different effects on piglet long-chain polyunsaturated fatty acid composition at birth and subsequent growth. $\mathrm{Br}$ J Nutr. 2001;86:21-30. https://doi.org/10.1079/bjn2001363.

31. Smits RJ, Luxford BG, Mitchell M, Nottle MB. Sow litter size is increased in the subsequent parity when lactating sows are fed diets containing n-3 fatty acids from fish oil. J Anim Sci. 2011;89:2731-8. https://doi.org/10.2527/ jas.2010-3593.

32. Tummaruk $P$, Sumransap $P$, Jiebna N. Fat and whey supplementation influence milk composition, backfat loss, and reproductive performance in lactating sows. Trop Anim Health Prod. 2014;46:753-8. https://doi.org/10.1 007/s11250-014-0559-8.

33. Pettigrew JE, Moser RL. Fat in swine nutrition. In: Miller ER, Ullrey DE, Lewis AJ, editors. Swine Nutrition. Stoneham: Butterworths; 1991. p. 133-45.

34. Strathe AV, Bruun TS, Zerrahn JE, Tauson AH, Hansen CF. The effect of increasing the dietary valine-to-lysine ratio on sow metabolism, milk production, and litter growth. J Anim Sci. 2016;94:155-64. https://doi.org/1 0.2527/jas.2015-9267.

35. Zhang T, Lg W, Hb S, Yan H, Lc Z, Liu X, et al. Hritabilities and genetic and phenotypic correlations of litter uniformity and litter size in Large White sows. J Integr Agric. 2016;15:848-54. https://doi.org/10.1016/s2095-3119(1 5)61155-8.

36. Kim SW, Weaver AC, Shen YB, Zhao Y. Improving efficiency of sow productivity: nutrition and health. J Anim Sci Biotechnol. 2013;4:26. https:// doi.org/10.1186/2049-1891-4-26.
37. Pournaras DJ, Le Roux CW. The effect of bariatric surgery on gut hormones that alter appetite. Diabetes Metab. 2009;35:508-12. https://doi.org/10.1016/ s1262-3636(09)73457-3.

38. Perry B, Wang Y. Appetite regulation and weight control: the role of gut hormones. Nutr Diabetes. 2012;2:e26. https://doi.org/10.1038/nutd.2011.21.

39. Steinert RE, Feinle-Bisset C, Geary N, Beglinger C. Digestive physiology of the pig symposium: secretion of gastrointestinal hormones and eating control. J Anim Sci. 2013;91:1963-73. https://doi.org/10.2527/jas.2012-6022.

40. Seimon RV, Feltrin KL, Meyer JH, Brennan IM, Wishart JM, Horowitz M, et al. Effects of varying combinations of intraduodenal lipid and carbohydrate on antropyloroduodenal motility, hormone release, and appetite in healthy males. Am J Physiol Regul Integr Comp Physiol. 2009;296:R912-20. https:// doi.org/10.1152/ajpregu.90934.2008.

41. Valent $\mathrm{D}$, Arroyo L, Fabrega E, Font IFM, Rodriguez-Palmero M, MorenoMunoz JA, et al. Effects of a high-fat-diet supplemented with probiotics and omega3-fatty acids on appetite regulatory neuropeptides and neurotransmitters in a pig model. Benef Microbes. 2020;11:347-59. https:// doi.org/10.3920/BM2019.0197.

42. Callahan HS, Cummings DE, Pepe MS, Breen PA, Matthys CC, Weigle DS Postprandial suppression of plasma ghrelin level is proportional to ingested caloric load but does not predict intermeal interval in humans. J Clin Endocrinol Metab. 2004;89:1319-24. https://doi.org/10.1210/jc.2003-031267.

43. Kaviani S, Cooper JA. Appetite responses to high-fat meals or diets of varying fatty acid composition: a comprehensive review. Eur I Clin Nutr. 2017;71:1154-65. https://doi.org/10.1038/ejcn.2016.250.

44. Feltrin KL, Little TJ, Meyer JH, Horowitz M, Smout AJ, Wishart J, et al. Effects of intraduodenal fatty acids on appetite, antropyloroduodenal motility, and plasma CCK and GLP-1 in humans vary with their chain length. Am J Physiol Regul Integr Comp Physiol. 2004;287:R524-33. https://doi.org/10.11 52/ajpregu.00039.2004.

45. Relling AE, Reynolds CK. Abomasal infusion of casein, starch and soybean oi differentially affect plasma concentrations of gut peptides and feed intake in lactating dairy cows. Domest Anim Endocrinol. 2008;35:35-45. https://doi. org/10.1016/.domaniend.2008.01.005.

46. Degen L, Drewe J, Piccoli F, Grani K, Oesch S, Bunea R, et al. Effect of CCK-1 receptor blockade on ghrelin and PYY secretion in men. Am J Physiol Regul Integr Comp Physiol. 2007;292:R1391-9. https://doi.org/10.1152/ajpregu. 00734.2006.

47. Leung K. 4-[(18) F]Fluorobenzoyl-Arg-Arg-Natl-Cys-Tyr-Cit-Lys-d-Lys-Pro-TyrArg-Cit-Cys-Arg-NH (2). Molecular Imaging and Contrast Agent Database (MICAD). National Center for Biotechnology Information (US): Bethesda (MD); 2004.

48. Cummings $D E$, Overduin J. Gastrointestinal regulation of food intake. J Clin Invest. 2007;117:13-23. https://doi.org/10.1172/JCl30227.

49. Estienne MJ, Harper AF, Kozink DM, Knight JW. Serum and milk concentrations of leptin in gilts fed a high- or low-energy diet during gestation. Anim Reprod Sci. 2003;75:95-105. https://doi.org/10.1016/s03 78-4320(02)00227-0.

50. Estienne MJ, Harper AF, Barb CR, Azain MJ. Concentrations of leptin in serum and milk collected from lactating sows differing in body condition. Domest Anim Endocrinol. 2000;19:275-80. https://doi.org/10.1016/s0739-724 0(00)00082-5.

51. Zhang XY, Wang DH. Different physiological roles of serum leptin in the regulation of energy intake and thermogenesis between pregnancy and lactation in primiparous Brandt's voles (Lasiopodomys brandtii). Comp Biochem Physiol C Toxicol Pharmacol. 2008;148:390-400. https://doi.org/10.1 016/j.cbpc.2008.01.013.

52. Barb CR, Hausman GJ, Czaja K. Leptin: a metabolic signal affecting central regulation of reproduction in the pig. Domest Anim Endocrinol. 2005;29: 186-92. https://doi.org/10.1016/j.domaniend.2005.02.024.

53. Lin X, Azain M, Odle J. Lipids and lipid utilization in swine. In: LI Chiba, editor. Sustainable swine nutrition. Oxford: Blackwell Publishing Ltd.; 2013. p. 59-79.

54. Van Dam RM, Seidell JC. Carbohydrate intake and obesity. Eur J Clin Nutr. 2007;61 (Suppl 1):S75-99. https://doi.org/10.1038/sj.ejcn.1602939.

55. Ackroff K, Sclafani A. Oral and postoral determinants of dietary fat appetite. In: Montmayeur JP, Le Coutre J, editors. Fat detection: Taste, texture, and post ingestive effects. Boca Raton: CRC Press/Taylor \& Francis; 2010.

56. Wang XJ, Xu SH, Liu L, Song ZG, Jiao HC, Lin H. Dietary fat alters the response of hypothalamic neuropeptide $\mathrm{Y}$ to subsequent energy intake in 
broiler chickens. J Exp Biol. 2017;220:607-14. https://doi.org/10.1242/jeb.143 792.

57. Van den Brand H, Heetkamp MJ, Soede NM, Schrama JW, Kemp B. Energy balance of lactating primiparous sows as affected by feeding level and dietary energy source. J Anim Sci. 2000;78:1520-8. https://doi.org/10.2527/2 000.7861520x.

58. Quiniou N, Richard S, Mourot J, Etienne M. Effect of dietary fat or starch supply during gestation and/or lactation on the performance of sows, piglets' survival and on the performance of progeny after weaning. Animal. 2008:2:1633-44. https://doi.org/10.1017/S1751731108002991.

59. Yen JT, Cromwell GL, Allee GL, Calvert CC, Crenshaw TD, Miller ER. Value of raw soybeans and soybean oil supplementation in sow gestation and lactation diets: a cooperative study. J Anim Sci. 1991;69:656-63. https://doi. org/10.2527/1991.692656x.

60. Booth PJ. Metabolic influences on hypothalamic-pituitary-ovarian function in the pig. Suppl J Reprod Fertil Suppl. 1990;40:89-100.

61. Leibowitz SF, Akabayashi A, Alexander JT, Wang J. Gonadal steroids and hypothalamic galanin and neuropeptide Y: role in eating behavior and body weight control in female rats. Endocrinology. 1998;139:1771-80. https://doi.org/10.1210/endo.139.4.5867.

62. Frisch M, Hjalgrim H. Re: Nonmelanomatous skin cancer following cervical, vaginal, and vulvar neoplasms: etiologic association. J Natl Cancer Inst. 1999; 91:565-6. https://doi.org/10.1093/jnci/91.6.565.

63. Hilakivi-Clarke L, Cho E, Onojafe I. High-fat diet induces aggressive behavior in male mice and rats. Life Sci. 1996;58:1653-60. https://doi.org/10.1016/ 0024-3205(96)00140-3.

64. Schneider JE. Energy balance and reproduction. Physiol Behav. 2004;81:289317. https://doi.org/10.1016/j.physbeh.2004.02.007.

65. Mikhael S, Punjala-Patel A, Gavrilova-Jordan L. Hypothalamic-pituitaryovarian axis disorders impacting female fertility. Biomedicines. 2019;7(1):5. https://doi.org/10.3390/biomedicines7010005.

66. Frisch RE. The right weight: body fat, menarche and ovulation. Baillieres Clin Obstet Gynaecol. 1990;4:419-39. https://doi.org/10.1016/s0950-3552(05)803 02-5.

67. Straw BE, Dewey $C E$, Bürgi EJ, Duran CO. Effects of extensive cross fostering on performance of pig on a farm. J Am Vet Med Assoc. 1998;212:855-6.

68. Calderón Díaz JA, García Manzanilla E, Diana A, Boyle LA. Cross-Fostering Implications for Pig Mortality. Welf Perform Front Vet Sci. 2018;5:123. https:// doi.org/10.3389/fvets.2018.00123.

69. Brogden RN, Goa KE. Adapalene. A review of its pharmacological properties and clinical potential in the management of mild to moderate acne. Drugs. 1997;53:511-9. https://doi.org/10.2165/00003495-199753030-00010.

70. Huting AMS, Almond K, Wellock I, Kyriazakis I. What is good for small piglets might not be good for big piglets: The consequences of cross-fostering and creep feed provision on performance to slaughter. J Anim Sci. 2017;95: 4926-44. https://doi.org/10.2527/jas2017.1889.

71. Zhang X, Wang M, He T, Long S, Guo Y, Chen Z. Effect of Different CrossFostering Strategies on Growth Performance, Stress Status and Immunoglobulin of Piglets. Animals (Basel). 2021;11. https://doi.org/10.33 90/ani11020499.

72. Farmer C. Review: Mammary development in lactating sows: the importance of suckling. Animal. 2019;13:s20-5. https://doi.org/10.1017/S1751 731118003464.

73. Bauer LS, Filer $L J$. Influence of body composition of weaning pigs on survival under stress. J Nutr. 1959;69:128-34. https://doi.org/10.1093/jn/ 69.2.128.

74. Rosero DS, Boyd RD, Odle J, Van Heugten E. Optimizing dietary lipid use to improve essential fatty acid status and reproductive performance of the modern lactating sow: a review. J Anim Sci Biotechnol. 2016;7:34. https:// doi.org/10.1186/s40104-016-0092-x.

Ready to submit your research? Choose BMC and benefit from:

- fast, convenient online submission

- thorough peer review by experienced researchers in your field

- rapid publication on acceptance

- support for research data, including large and complex data types

- gold Open Access which fosters wider collaboration and increased citations

- maximum visibility for your research: over $100 \mathrm{M}$ website views per year

At BMC, research is always in progress.

Learn more biomedcentral.com/submissions 